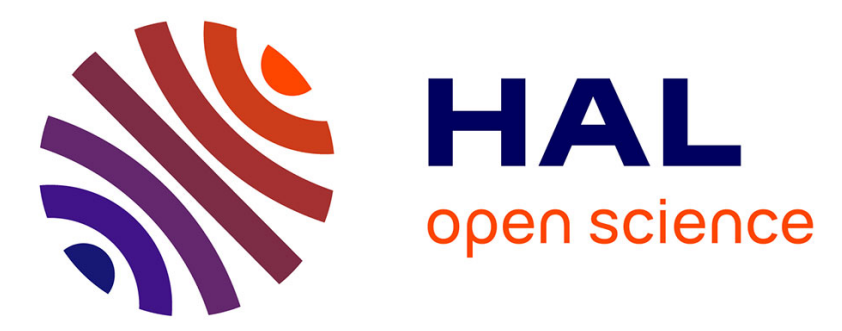

\title{
Fully Biobased Vitrimers from Glycyrrhizic Acid and Soybean Oil for Self-Healing, Shape Memory, Weldable, and Recyclable Materials
}

Jianqiao Wu, Xia Yu, Hao Zhang, Junbo Guo, Jun Hu, Min-Hui Li

\section{- To cite this version:}

Jianqiao $\mathrm{Wu}$, Xia Yu, Hao Zhang, Junbo Guo, Jun Hu, et al.. Fully Biobased Vitrimers from Glycyrrhizic Acid and Soybean Oil for Self-Healing, Shape Memory, Weldable, and Recyclable Materials. ACS Sustainable Chemistry \& Engineering, 2020, 8 (16), pp.6479-6487. 10.1021/acssuschemeng.0c01047 . hal-03051793

\section{HAL Id: hal-03051793 https://hal.science/hal-03051793}

Submitted on 22 Dec 2020

HAL is a multi-disciplinary open access archive for the deposit and dissemination of scientific research documents, whether they are published or not. The documents may come from teaching and research institutions in France or abroad, or from public or private research centers.
L'archive ouverte pluridisciplinaire HAL, est destinée au dépôt et à la diffusion de documents scientifiques de niveau recherche, publiés ou non, émanant des établissements d'enseignement et de recherche français ou étrangers, des laboratoires publics ou privés. 


\title{
Fully Biobased Vitrimers from Glycyrrhizic Acid
}

\section{and Soybean Oil for Self-Healing, Shape Memory,}

\section{Weldable and Recyclable Materials}

\author{
Jianqiao Wu, ${ }^{\dagger}$ Xia Yu, ${ }^{\dagger}$ Hao Zhang, ${ }^{\dagger}$ Junbo Guo, ${ }^{\dagger}$ Jun Hu, ${ }^{\dagger}{ }^{\dagger}$ Min-Hui Li, ${ }^{*}{ }^{+}$
}

$\dagger$ Beijing Advanced Innovation Center for Soft Matter Science and Engineering, Beijing University of Chemical Technology, North Third Ring Road 15, Chaoyang District, Beijing 100029, China.

Institut de Recherche de Chimie Paris, Chimie ParisTech, PSL Research University, CNRS, 11 rue Pierre et Marie Curie, Paris 75005, France.

\section{*Corresponding Authors \\ Email: jhu@mail.buct.edu.cn (Jun Hu); min-hui.li@chimieparistech.psl.eu (Min-Hui Li).}

\begin{abstract}
Vitrimers are covalent polymer networks that can change their topology through thermally activated bond exchange reactions. In this work fully biobased and recyclable vitrimers were developed from epoxidised soybean oil (ESO) and natural glycyrrhizic acid (GL) as it was without additional chemical modification, which avoided the use of nonrenewable petroleum resources and resolved the disposal problems of materials. Due to the unique rigid skeleton of GL, ESO/GL vitrimers showed good thermal stability and mechanical properties. Driven by the
\end{abstract}


transesterification-induced topological network rearrangements, these ESO/GL vitrimers exhibited high performance of welding, repairing and shape memory. They were also recyclable and chemically degradable by ethylene glycol. More importantly, these vitrimers could be used as repairable and recyclable adhesives.

KEYWORDS: biobased vitrimers, glycyrrhizic acid, transesterification, shape memory polymers, recyclable adhesives

\section{INTRODUCTION}

Thermosetting polymers such as Bakelite are permanently cross-linked materials which present excellent thermal stability, dimensional stability, chemical resistance and mechanical properties, and have been widely used in coatings, composites, adhesives and electronic packaging over the past century. ${ }^{1-4}$ But they cannot be reprocessed and reshaped once synthesized. On the other hand, non-cross-linked polymers and those with reversible crosslinks are reprocessable. However, they are soluble and have modest chemical resistance. The concept of vitrimer invented by the group of Leibler ${ }^{5-7}$ in 2011 has addressed elegantly this dilemma. Vitrimers are covalent polymer networks that can change their topology through thermally activated bond exchange reactions. At high temperatures, vitrimers can flow and behave like viscoelastic liquids. Therefore, they can be reprocessed and recycled as thermoplastics. At low temperatures, exchange reactions are very slow and vitrimers behave like classical thermosets. Having the properties of both thermosets and thermoplastics, vitrimers have immerged as appealing candidates for self-healing materials, ${ }^{8-10}$ shape memory polymers, ${ }^{11-13}$ soft actuators, ${ }^{14-17}$ and 3D printing thermosets. ${ }^{18,19}$

At the same time, the interest in polymers from renewable resources has grown incessantly both in academia and in industry. The green chemistry connotations in the conception of polymer 
materials are opening the way to the sustainable development of new generation of polymers. ${ }^{20,21}$ For vitrimer preparation, renewable resources from vegetal, animal, or fungal have been used more and more as the building blocks, ${ }^{22-30}$ which can reduce the consumption of non-renewable resources and may endow materials with biocompatible and biodegradable properties. For example, Zhang and co-workers prepared a series of vitrimer materials from eugenol, ${ }^{23}$ lignin,${ }^{24}$ vanillin, ${ }^{25}$ and guaiacol, ${ }^{25}$ which were weldable, reprocessable and self-healable. The group of Zhu found that the Schiff base covalent vitrimers prepared from vanillin exhibited the high performance beyond the ones from commercial bisphenol A epoxy resin, ${ }^{26-28}$ and could be facilely recycled from carbon fiber reinforced composites. ${ }^{27,28}$ However, in these reported works tedious chemical modifications on biological resources were necessary to offer reactive sites for curing. Therefore, we find necessary to develop the fully biobased vitrimers using renewable resources without excessive chemical modification before curing. In this paper, we report on the preparation of fully biobased vitrimers from epoxidised soybean oil (ESO) and natural glycyrrhizic acid (GL) based on the transesterification reactions. ${ }^{31}$

Glycyrrhizic acid (GL) is a natural triterpene saponin found mainly in licorice roots and has been widely applied as food sweeteners and medicinal ingredients. ${ }^{32-35}$ It has a rigid hydrophobic triterpenoid and a hydrophilic diglucuronic unit (Figure 1), which allow GL to be easily incorporated into the biocompatible self-assembled materials. ${ }^{36-39} \mathrm{GL}$ contains three carboxylic acid groups and can react with epoxy directly as hardener. In addition, the multiple hydroxyl groups in GL are also beneficial to the transesterification reactions of epoxy-acid vitrimer networks. ${ }^{40}$ Moreover, the unique rigid skeleton of GL should be able to improve the thermal stability and mechanical properties of materials. On the other hand, epoxidised soybean oil (ESO), as a common plasticizer in the plastics industry, is low-cost, non-toxic and non-volatile substance, 
which can be crosslinked with amines, ${ }^{41}$ carboxylic acid, ${ }^{42}$ and anhydrides ${ }^{43}$ to form tridimensional networks. ${ }^{44}$ Taking advantage of the properties of both GL and ESO, we prepared here the fully biobased vitrimers from ESO and GL with different ESO/GL stoichiometric ratios. Both materials come from food grade sources and are used directly without additional chemical modification. The schematic diagram of the curing and network topological rearrangements is shown in Figure. 1. During the curing process the carboxyl groups in GL attacked the epoxy on ESO to form ester bonds with the generation of additional hydroxyl groups, and the hydroxyl groups in GL can also react with epoxy to afford ether bonds, etc. (Scheme S1), resulting in the formation of cross-linked networks. In the presence of 1,5,7-triazabicyclo[4.4.0]dec-5-ene (TBD) catalysis, transesterification reactions took place at elevated temperature to induce the topological rearrangements of networks. The ESO/GL networks were studied in detail by stress relaxation tests, creep-recovery test, thermodilatometry tests, etc., and were evidenced to be weldable, repairable, reprocessable and recyclable vitrimers. Moreover, we used ESO/GL vitrimers to produce a repairable and recyclable adhesive. This fully biobased materials containing $100 \%$ renewable carbon content will enrich the species of biobased vitrimers and show a potential for biomedical applications.
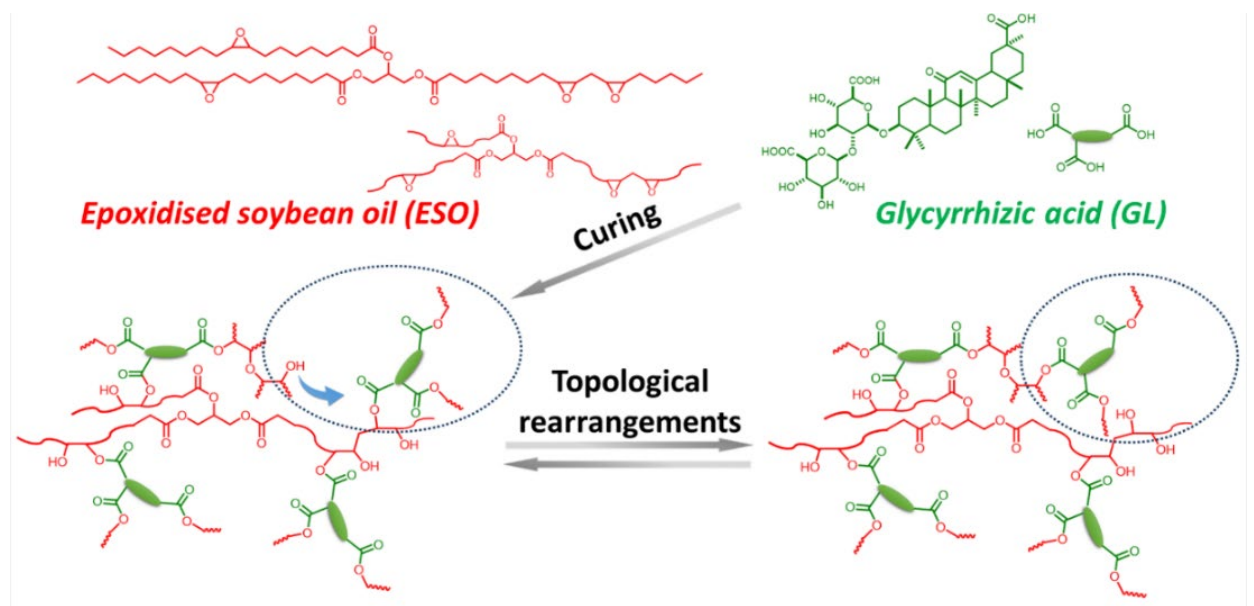
Figure 1. Schematic illustration of chemical structures of ESO and GL, curing reaction and topological rearrangements of ESO/GL networks.

\section{EXPERIMENTAL SECTION}

Materials. Epoxidised soybean oil (ESO, Macklin, AR), glycyrrhizic acid (GL, Energy Chemical, 95\%), 1,5,7-triazabicyclo[4.4.0]dec-5-ene (TBD, Ark Pharm, 98\%) and ethylene glycol (EG, Inno Chem, 99\%) were used directly as purchased without further purifying. Epoxidised soybean oil (ESO, Macklin, AR) contained 4 epoxy groups on average as indicated by the supplyer and confirmed by ${ }^{1} \mathrm{H}$ NMR (Figure S1).

Preparation of ESO/GL networks. As shown in Figure S2, TBD (5\% molar ratio to carboxylic acid) was first added into ESO using a beaker at $100^{\circ} \mathrm{C}$, and then the solution was heated to $120^{\circ} \mathrm{C}$. Upon addition of GL, the mixture was poured into a mould with a dimension of $100 \mathrm{~mm} \times 80 \mathrm{~mm}$ $\times 1 \mathrm{~mm}$. Finally, the mould was put into a press vulcanizer and cured at $160^{\circ} \mathrm{C}$ for $1 \mathrm{~h}, 180^{\circ} \mathrm{C}$ for $2 \mathrm{~h}$, and $200^{\circ} \mathrm{C}$ for $2 \mathrm{~h}$ at a pressure of $200 \mathrm{~kg} / \mathrm{cm}^{2}$.

Gel content test. The dry sample $\left(\sim 30 \mathrm{mg}, m_{0}\right)$ was immersed in $5 \mathrm{~mL}$ acetonitrile for $20 \mathrm{~h}$. After $20 \mathrm{~h}$, the samples were dried in a vacuum oven at $60^{\circ} \mathrm{C}$ for $10 \mathrm{~h}$ and then weighted $\left(m_{1}\right)$. The gel content was calculated according to the following equation,

$$
\text { Gel contents }(\%)=\frac{m_{1}}{m_{0}} \times 100 \%
$$

Swelling test. The swelling ratio was measured by immerging the sample $\left(\sim 30 \mathrm{mg}, \mathrm{m}_{0}\right)$ in acetonitrile at room temperature. When the absorption reached equilibrium, the sample was taken out of the solution. The excessive surface solvent was removed with a filter paper, and the swollen sample was weighted $\left(m_{1}\right)$. The swelling ratio was calculated according to the following equation, 


$$
\text { Swelling ratio }(\%)=\frac{m_{1}-m_{0}}{m_{0}} \times 100 \%
$$

Dynamic mechanical analysis. Dynamic mechanical properties were measured using a dynamic mechanical analyzer (DMA, TA-Q800) in tension mode. The sample with a dimension of $30 \mathrm{~mm}$ $\times 5 \mathrm{~mm} \times 1 \mathrm{~mm}$ was scanned from -50 to $200^{\circ} \mathrm{C}$ at a heating rate of $5^{\circ} \mathrm{C} / \mathrm{min}$. The amplitude was set at $5 \mu \mathrm{m}$ and the frequency was $1 \mathrm{~Hz}$.

Stress relaxation test. Stress relaxation was measured using DMA (TA-Q800). The sample dimension was $30 \mathrm{~mm} \times 5 \mathrm{~mm} \times 1 \mathrm{~mm}$. The sample was heated to appointed temperature and soaked for $15 \mathrm{~min}$ with a static force $(0.01 \mathrm{~N})$. After that, an instantaneous strain of $5 \%$ was forced to the material. The stress and modulus was detected for several hours until it achieved the equilibrium.

Creep-recovery test. Creep-recovery behavior was measured using DMA (TA-Q800). The sample dimension was $30 \mathrm{~mm} \times 5 \mathrm{~mm} \times 1 \mathrm{~mm}$. Initially the sample was heated to $200^{\circ} \mathrm{C}$ and soaked for $15 \mathrm{~min}$, and then a constant force was added to stretch material (stress constant at 8 $\mathrm{kPa}$ ). After $1 \mathrm{~h}$, it was revoked and the material recovered for another $1 \mathrm{~h}$.

Thermodilatometry test. Thermodilatometry was measured using DMA (TA-Q800) in controlled force tension mode. The sample dimension was $30 \mathrm{~mm} \times 5 \mathrm{~mm} \times 1 \mathrm{~mm}$. A constant force was added to stretch material which made the stress constant at $2 \mathrm{kPa}$. Sample was heated to $250^{\circ} \mathrm{C}$ as a heating rate of $5^{\circ} \mathrm{C} / \mathrm{min}$.

Welding test. Welding property was studied using an oven at $200^{\circ} \mathrm{C}$. Three pieces were assembled into an " $\mathrm{H}$ " pattern without any pressure at $200^{\circ} \mathrm{C}$ for $15 \mathrm{~min}$. 
Repairing test. Repairing property was studied using an optical microscope (UPT200I). The sample was cracked using a knife and repaired at an oven at $200^{\circ} \mathrm{C}$. A glass slide was added on the sample to offer a small pressure.

Shape memory test. Shape memory property was characterized using DMA (TA-Q800) in the tension mode. The sample dimension was $30 \mathrm{~mm} \times 5 \mathrm{~mm} \times 1 \mathrm{~mm}$. Initially, the sample was equilibrated at $60^{\circ} \mathrm{C}$ (above $T_{g}$ ) for $40 \mathrm{~min}$. Subsequently, a constant force of $0.03 \mathrm{~N}$ was applied to the sample and the temperature was decreased to $0^{\circ} \mathrm{C}$ (below $T_{g}$ ) at a cooling rate of $5^{\circ} \mathrm{C} / \mathrm{min}$. When the temperature reached $0^{\circ} \mathrm{C}$, the constant force was removed, and the sample was heated back to $60^{\circ} \mathrm{C}$ at a heating rate of $5^{\circ} \mathrm{C} / \mathrm{min}$. The above steps were repeated for three times and the displacements were recorded during the test.

Physical recycle. Physical recycle properties were studied using DMA (TA-Q800). The sample pieces were gathered and put into a mould on a press vulcanizer at $200^{\circ} \mathrm{C}$ for $135 \mathrm{~min}$ at 200 $\mathrm{kg} / \mathrm{cm}^{2}$ pressure to form new samples. The sample dimension was $30 \mathrm{~mm} \times 5 \mathrm{~mm} \times 1 \mathrm{~mm}$. All the samples were cooled to $-40^{\circ} \mathrm{C}$ for soaking $15 \mathrm{~min}$ and then tested using DMA stress-strain mode.

Lap-shear test. Lap-shear measurements were carried out on testing machine (UTM5205XHD) according to ISO 4587: 2003 standard. The aluminum sheets were $100 \mathrm{~mm} \times 25 \mathrm{~mm} \times 1 \mathrm{~mm}$, and cleaned by soap water, Di-water and isopropanol before use. Initially, uncured $\mathrm{ESO} / \mathrm{GL}(\mathrm{R}=0.5$, TBD 5 mol\%) mixture was loaded between two aluminum sheets, and the overlap area was 12.5 $\mathrm{mm} \times 25 \mathrm{~mm}$ with a thickness of the interval $0.2 \mathrm{~mm}$. After that, the curing was performed on a press vulcanizer with the same condition as ESO/GL networks. For repairing process (Mode I), the failed two halves of adhesive were re-bonded together through hot press at $200^{\circ} \mathrm{C}$ with 200 $\mathrm{kg} / \mathrm{cm}^{2}$ pressure for $135 \mathrm{~min}$. For recycled process (Mode II), the broken samples and redundant 
cured samples were collected and grinded into powders. After that, $\sim 70 \mathrm{mg}$ of them was loaded on aluminum, followed by hot press at $200^{\circ} \mathrm{C}$ for $135 \mathrm{~min}$ at $200 \mathrm{~kg} / \mathrm{cm}^{2}$ pressure. At least five repeats were performed for each sample.

Chemical degradable test. Chemical degradable property was investigated by using ethylene glycol (EG, $5 \mathrm{~mL}$ ) in vials at $180^{\circ} \mathrm{C}$. The sample was cut to $20 \sim 30 \mathrm{mg}$ pieces $\left(m_{0}\right)$, and then immersed in EG at $180^{\circ} \mathrm{C}$. The sample was taken out of the vial at $1 \mathrm{~h}, 2 \mathrm{~h}$, till to $14 \mathrm{~h}$, and dried at $180^{\circ} \mathrm{C}$ and weighted $\left(m_{1}\right)$. The relative weight was calculated according to the following equation and at least three samples were studied to get an average value.

$$
\text { Relative weight }(\%)=\frac{m_{1}}{m_{0}} \times 100 \%
$$

\section{RESULTS AND DISCUSSION}

Curing and structure characterization of ESO/GL networks. The curing reactions of ESO and GL were performed in the presence of TBD (5\% molar ratio to carboxylic acid) which served as a catalyst for the transesterification reactions. Due to the poor solubility of GL in ESO, the stoichiometric ratios $(\mathrm{R}=$ carboxylic acid/epoxy) were set up as $0.4,0.5$ and 0.6 . In this case, the excess epoxy groups would react with hydroxyl groups to offer a fraction of partial permanent linkages. Meanwhile, a control system was designed by using glycyrrhetinic acid (GA) to react with ESO for verifying the curing reactivity of all three carboxyl groups of GL (Figure S3). As can be seen from the structures of GA and GL in Figure S3a, all three carboxyl groups of GL are alicyclic with the similar chemical environment, and their $p \mathrm{~K}_{\mathrm{a}}$ values are 3.98, 4.62 and 5.17 for

carboxyl group I, II, and III, respectively, ${ }^{45}$ while only carboxyl group III exists in GA. That is to say, carboxyl group III is less reactive than carboxyl group I and II. The control results showed that carboxyl group III can easily attack epoxy group to form polymer networks supported by the 
exothermic peak at $210^{\circ} \mathrm{C}$ (Figure S3b) and the obvious glass transition around $53^{\circ} \mathrm{C}$ after curing (Figure S3c). Because there were excess epoxy groups in ESO/GL systems, it was assumed that all three carboxyl groups of GL could participate in the curing reactions.

In order to establish the curing process, differential scanning calorimeter (DSC) was used to determine the phase transition and the reaction peaks in the range from 50 to $250^{\circ} \mathrm{C}$ with a heating rate $5^{\circ} \mathrm{C} / \mathrm{min}$. As shown in Figure 2a, there was a broad endothermic peak at $195^{\circ} \mathrm{C}$ for the melting point of GL, while no peak for liquid ESO. When heating the mixture of GL and ESO ( $\mathrm{R}=0.5)$ without catalyst, a broad exothermic peak at $180^{\circ} \mathrm{C}$ was observed clearly with enthalpy of $165 \mathrm{~J} / \mathrm{g}$, indicating the reaction between carboxylic acid and epoxy groups and the formation of crosslinked networks. As for the mixture of ESO/GL ( $\mathrm{R}=0.5$, TBD $5 \mathrm{~mol} \%)$, a broad exothermic peak at a little higher temperature $\left(200^{\circ} \mathrm{C}\right)$ was detected as shown in Figure 2a, indicating again the curing reaction and the formation of crosslinked networks. To ensure no degradation of catalyst during the curing reactions at such high temperature, the thermal stability of TBD and ESO/GL/TBD mixture were studied using thermogravimetric analyzer (TGA) in Figure S4. Generally, free TBD monomer at high temperature (above $150^{\circ} \mathrm{C}$ ) can cause side reactions and degradation (Figure $\mathrm{S} 4 \mathrm{a})$, whereas the mixture of $\mathrm{ESO} / \mathrm{GL} / \mathrm{TBD}(\mathrm{R}=0.5$, TBD $5 \mathrm{~mol} \%, 0.945 \mathrm{wt} \%)$ showed well thermal stability with a $0.945 \%$ degradation at $215^{\circ} \mathrm{C}$ (Figure S4b), revealing that TBD did not decompose as the pure one. This phenomenon also existed even for higher TBD content $(\mathrm{R}=0.5$, TBD content: $50 \mathrm{~mol} \%, 8.6 \mathrm{wt} \%$ ), where the $8.6 \mathrm{wt} \%$ loss was achieved at $269^{\circ} \mathrm{C}$ (Figure S4c). According to the above TGA results and other reported of TBD, ${ }^{46-48}$ it was assumed that TBD may form a transition structure with carboxyl group of GL as shown in Scheme S2, thus enhancing the thermo stability of TBD in comparison with free TBD monomer. However, this transition structure may hinder the curing reactions, which consequently caused the temperature of exothermic peak 
of of ESO/GL with TBD a little higher than mere ESO/GL. As can be seen from the DSC results (Figure 2a), the exothermic peak of curing reaction of ESO/GL ranged from 170 to $230^{\circ} \mathrm{C}$. In this case, in order to make the curing process cover this temperature range and avoid the degradation of $\mathrm{GL}, 160^{\circ} \mathrm{C}, 180^{\circ} \mathrm{C}$, and $200^{\circ} \mathrm{C}$ were set up as the pre-curing, curing, and post-curing temperatures, respectively. The pre-curing temperature $\left(160^{\circ} \mathrm{C}\right)$ was used to make the initial crosslinking slow and prevent flash polymerization, while the post-curing temperature $\left(200^{\circ} \mathrm{C}\right)$ was used to guarantee the complete reaction and to remove internal stress of materials. Meanwhile, pressure was also necessary for the curing process ${ }^{24,30}$ because it not only made resin flow but also exhausted voids to help vitrimer preparation. Given above, the curing process was set as " $160^{\circ} \mathrm{C}$ $/ 1 \mathrm{~h}+180^{\circ} \mathrm{C} / 2 \mathrm{~h}+200^{\circ} \mathrm{C} / 2 \mathrm{~h}$ " at a pressure of $200 \mathrm{~kg} / \mathrm{cm}^{2}$ for ESO/GL with different stoichiometric ratios and $5 \mathrm{~mol} \%$ of TBD.

The curing reaction between ESO and GL in ESO/GL mixture was further confirmed by FTIR, where peaks of epoxy at 843 and $823 \mathrm{~cm}^{-1}$ disappeared after curing, revealing the complete consumption of epoxy groups (Figure 2b). ${ }^{22}$ Additionally, the signals at 3430, 2925, 1740, 1730, and $1655 \mathrm{~cm}^{-1}$ were assigned to hydroxyl, methylene, ester, carboxyl and ketone groups from backbones of ESO and GL, respectively (Figure S5). Notably, the materials were black after curing which may due to the oxidation of trace diglucuronic units on GL. For confirming this assumption, a control experiment was performed by using carbenoxolone (CBX, Figure S6a) to react with ESO under the similar curing condition as ESO/GL. As shown in Figure S6b, the cured sample of $\mathrm{ESO} / \mathrm{CBX}$ was transparent, implying that the black color of ESO/GL vitrimer was attributed to the oxidation reaction of trace diglucuronic units. 

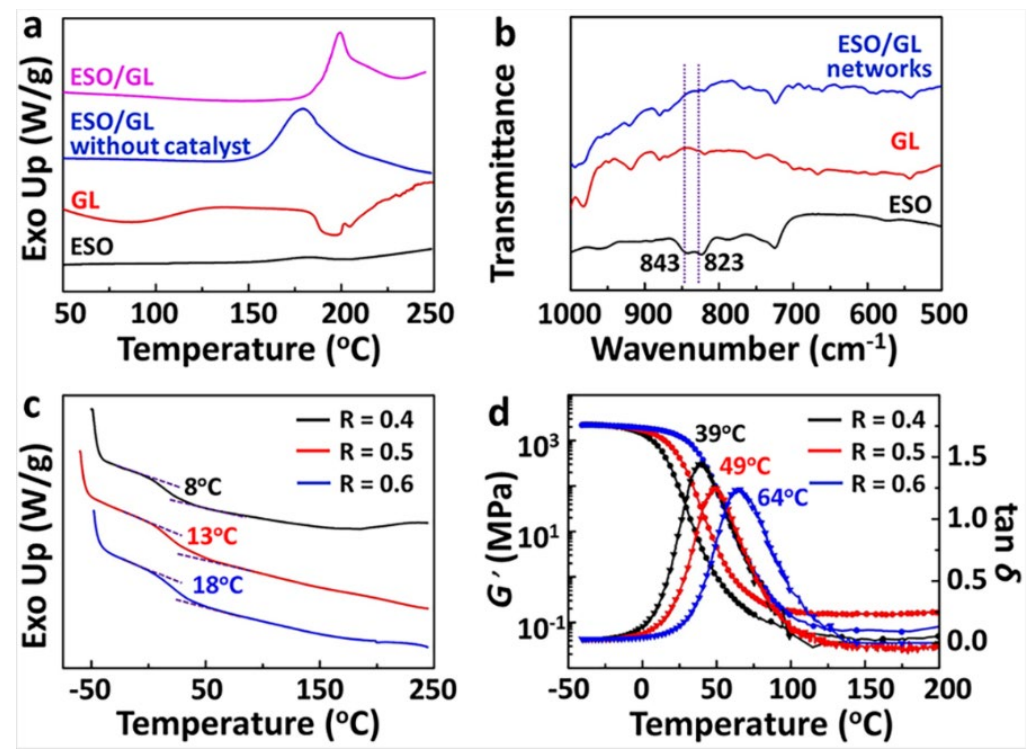

Figure 2. (a) DSC curves of ESO, GL, ESO/GL without catalyst $(\mathrm{R}=0.5)$ and $\mathrm{ESO} / \mathrm{GL}(\mathrm{R}=0.5$, TBD $5 \mathrm{~mol} \%$ ) at a heating rate of $5^{\circ} \mathrm{C} / \mathrm{min}$. (b) FTIR spectra of ESO, GL and ESO/GL networks $(\mathrm{R}=0.5$, TBD $5 \mathrm{~mol} \%)$. (c) DSC curves of ESO/GL networks $(\mathrm{R}=0.4,0.5,0.6$; TBD $5 \mathrm{~mol} \%)$ $\left(20^{\circ} \mathrm{C} / \mathrm{min}\right)$. (d) Storage modulus (circle) and $\tan \delta$ (triangle) of ESO/GL networks $(\mathrm{R}=0.4,0.5$, 0.6; TBD $5 \mathrm{~mol} \%)$.

The formulations and thermal properties of ESO/GL vitrimers were summarized in Table 1. Gel content and swelling ratio were investigated for proving the effective crosslinking. All networks exhibited similar gel contents in the range from 89 to $91 \%$ and had low swelling ratios at room temperature from 14 to $17 \%$, similar to those of thermosets with high crosslinking density. Moreover, the swelling ratio decreased as expected when the loading of GL increased, i.e., when the concentration of carboxyl and hydroxy groups increased. 
Table 1 Compositions and thermal properties of ESO/GL networks containing $5 \mathrm{~mol} \%$ of TBD.

\begin{tabular}{cccccc}
\hline $\mathrm{R}^{\mathrm{a}}$ & $\begin{array}{c}\text { Gel content } \\
(\%)^{\mathrm{b}}\end{array}$ & $\begin{array}{c}\text { Swelling ratio } \\
(\%)^{\mathrm{b}}\end{array}$ & $\begin{array}{c}T_{d 5} \\
\left({ }^{\circ} \mathrm{C}\right)^{\mathrm{c}}\end{array}$ & $\begin{array}{c}T_{g(\mathrm{DSC})} \\
\left({ }^{\circ} \mathrm{C}\right)^{\mathrm{d}}\end{array}$ & $\begin{array}{c}T_{g(\text { DMA })} \\
\left({ }^{\circ} \mathrm{C}\right)^{\mathrm{e}}\end{array}$ \\
\hline 0.4 & $89.0 \pm 1.0$ & $17.0 \pm 0.8$ & 315 & 8 & 39 \\
0.5 & $90.1 \pm 0.3$ & $16.1 \pm 0.8$ & 328 & 13 & 49 \\
0.6 & $90.9 \pm 0.4$ & $14.1 \pm 0.3$ & 314 & 18 & 64 \\
\hline
\end{tabular}

${ }^{\mathrm{a}} \mathrm{R}$ represents the stoichiometric ratio of carboxylic acid/epoxy. ${ }^{\mathrm{b}}$ The swelling ratio and gel content of ESO/GL networks were measured using acetonitrile as solvent. ${ }^{\mathrm{c}} \mathrm{The}$ temperature at $5 \mathrm{wt} \%$ loss (Figure S7). ${ }^{\mathrm{d}} T_{g}$ values determined from DSC (Figure 2c). ${ }^{\mathrm{e}}$ The peak temperature from $\tan \delta$ curve (Figure 2d).

To test the thermal stability of ESO/GL networks, TGA under nitrogen atmosphere was used. As shown in Figure S7 and Table 1, the temperature at $5 \%$ of weight loss $\left(T_{d 5}\right)$ for each material was above $310^{\circ} \mathrm{C}$, revealing a good thermal stability of ESO/GL networks that did not decompose under $300^{\circ} \mathrm{C}$. Glass transition temperature $\left(T_{g}\right)$ is a parameter acting as the upper limit temperature for the use as thermosets. The $T_{g}$ of ESO/GL networks measured by DSC were shown in Figure $2 \mathrm{c}$, the middle point of the steps at 8,13 , and $18^{\circ} \mathrm{C}$ being assigned as $T_{g}$ for ESO/GL networks with $\mathrm{R}=0.4,0.5$ and 0.6 , respectively. The gradient increase of $T_{g}$ with $\mathrm{R}$ value was mainly due to the rigid skeleton of GL in the networks. On one hand, the higher content of GL offered more reactive sites (carboxyl and hydroxyl groups) for curing reaction and caused an increase in crosslinking density as shown in the Table 1. On the other hand, the skeleton of GL made polymer chains more rigid, and could also increase the value of $T_{g}$. Indeed, the viscoelastic properties of $\mathrm{ESO} / \mathrm{GL}$ networks $(\mathrm{R}=0.4,0.5,0.6)$ were investigated using dynamic thermomechanical analysis (DMA). As shown in Figure. 2d, a clear transition from glass plateau to rubbery plateau was 
observed for each sample, and the storage modulus at glass plateau was $2200 \mathrm{MPa}$ for all three samples. Compared with the system based on ESO and citric acid with the storage modulus ranging from 600 to $400 \mathrm{MPa},{ }^{22}$ the higher storage modulus of our system was mainly due to the stiff structure of GL. The peaks of $\tan \delta$ at $39,49,64^{\circ} \mathrm{C}$ were assigned as $T_{g}$, and their variation tendency was consistent with the one observed by DSC, which further indicated that the rigid structure of GL and the high crosslinking density led to the increase of $T_{g}$. Such mild temperatures of $T_{g}$ are favorable for obtaining shape memory properties around room temperature.

Characterization of topological network rearrangements. The mechanism of transesterification reactions (TERs) was shown in Figure 1, where hydroxyl groups reacted with ester bonds to generate other hydroxyl groups and ester bonds, consequently resulting in the topological rearrangements of crosslinked networks. Since the breakage of old bonds and the formation of new bonds happened simultaneously, the rearrangements did not influence the crosslinking density of materials. ${ }^{5,8}$ The evidence of this thermally-activated TERs could be revealed by thermal stress relaxation experiment, which examined the stress as a function of an external applied strain to the materials. Figure 3a showed the evolution of the relaxation modulus of $\mathrm{ESO} / \mathrm{GL}$ networks ( $\mathrm{R}=0.5$, TBD $5 \mathrm{~mol} \%$ ) at $140,160,180$ and $200^{\circ} \mathrm{C}$, respectively, and the relaxation time $\left(\tau^{*}\right)$ was determined as the material relaxed to $1 / e$ of the initial modulus $\left(G / G_{0}=\right.$ 1/e). The $\tau^{*}$ was $28117 \mathrm{~s}(7.81 \mathrm{~h})$ at $140^{\circ} \mathrm{C}, 4118 \mathrm{~s}(1.14 \mathrm{~h})$ at $160^{\circ} \mathrm{C}, 1351 \mathrm{~s}(23 \mathrm{~min})$ at $180^{\circ} \mathrm{C}$, and $425 \mathrm{~s}(7 \mathrm{~min})$ at $200^{\circ} \mathrm{C}$, and the full stress relaxation was achieved after $9500 \mathrm{~s}(2.64 \mathrm{~h})$ at $180^{\circ} \mathrm{C}$, but only after $3200 \mathrm{~s}(53 \mathrm{~min})$ at $200^{\circ} \mathrm{C}$. The drop in relaxation time was explained by the acceleration of transesterification at high temperature. The suitable stress relaxation time of $\mathrm{ESO} / \mathrm{GL}(\mathrm{R}=0.5)$ benefitting from the flexible chains of ESO and the large amount of hydroxyl groups on GL ensured the material welding, repairing, reprocessing and recycling. 

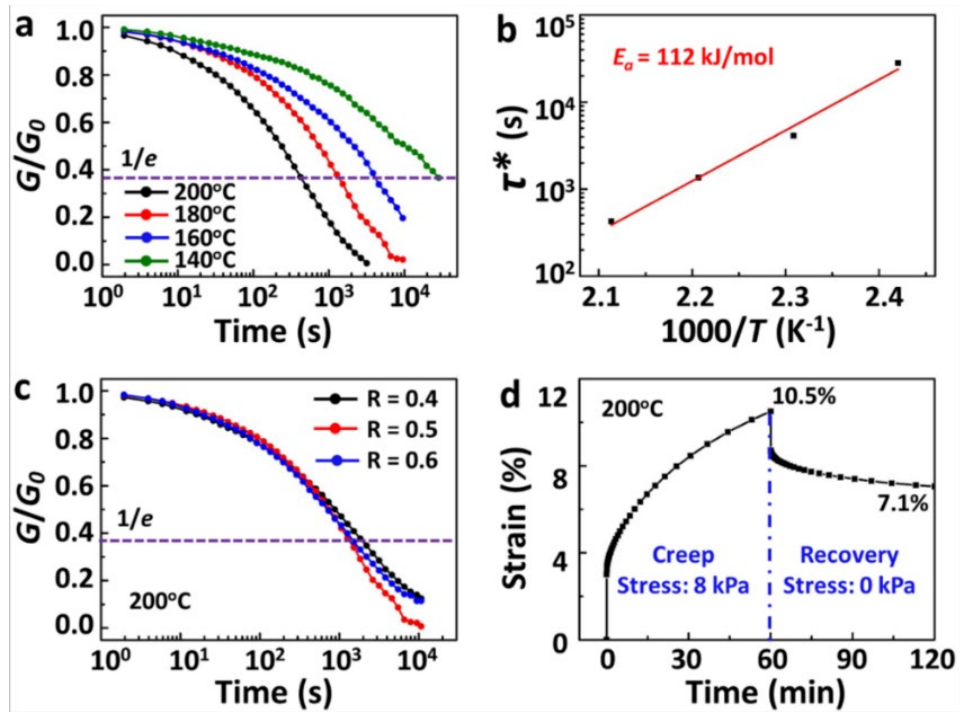

Figure 3. (a) Stress relaxation of ESO/GL networks $(\mathrm{R}=0.5$, TBD $5 \mathrm{~mol} \%)$ at different temperature $\left(200,180,160\right.$ and $\left.140^{\circ} \mathrm{C}\right)$ using DMA tension mode with the strain of 5\%. (b) Fitting of experimental values of relaxation times ( $\left.\tau^{*}\right)$ derived from (a) to an Arrhenius-type equation. (c) Stress relaxation of ESO/GL networks $(\mathrm{R}=0.4,0.5,0.6$; TBD $5 \mathrm{~mol} \%)$ at $200^{\circ} \mathrm{C}$ using DMA tension mode with the strain of 5\%. (d) Creep-recovery behavior of ESO/GL networks $(\mathrm{R}=0.5$, TBD $5 \mathrm{~mol} \%$ ) at $200^{\circ} \mathrm{C}$.

Analyzing in detail the relaxation process, we found the system relaxation followed a Maxwell model fitted by an Arrhenius-type equation:

$$
\ln \tau^{*}=\frac{E_{a}}{R T}-\ln A
$$

where $\tau^{*}$ is the relaxation time defined as the time needed to achieve a particular $G / G_{0}$ value $(1 / e)$ at a given temperature, $E_{a}$ is the activation energy of the bond exchange, $T$ is the experimental temperature, and $R$ is the universal gas constant. As shown in Figure 3b, the perfect fitting was obtained with $E_{a}$ around $112 \mathrm{~kJ} \mathrm{~mol}^{-1}$, which was in good agreement with the values reported by Leibler $^{5}$ and other researchers ${ }^{18,22,49,50}\left(69 \sim 150 \mathrm{~kJ} \mathrm{~mol}^{-1}\right)$. In addition, using Maxwell equation ${ }^{50,51}$ 
a topology freezing transition temperature (vitrification temperature, $T_{v}$ ) of ESO/GL networks (R $=0.5$, TBD $5 \mathrm{~mol} \%)$ was determined as $69^{\circ} \mathrm{C}$ (Figure $\mathrm{S} 8$ ).

Besides, the stress relaxation curves of ESO/GL networks with different stoichiometric ratios at $200^{\circ} \mathrm{C}$ were measured as shown in Figure 3c. Interestingly, the relaxation time of ESO/GL networks with $\mathrm{R}=0.6$ as well as with $\mathrm{R}=0.4$ was slightly higher than the one with $\mathrm{R}=0.5$. Normally, a lower $\mathrm{R}=0.4$ corresponded to a higher content of ESO and more flexible chains within networks, facilitating the TERs. However, with $\mathrm{R}=0.4$, the amount of reactive hydroxyl groups from GL decreased simultaneously. Consequently, the relaxation time of ESO/GL networks with different $\mathrm{R}=0.4,0.5$ and 0.6 was in the same order with only slight difference. As a matter of fact, the relaxation time was the result of the synergistic effect between the flexible chains and the hydroxyl groups. ${ }^{40,52}$ In the following study, we continued to select ESO/GL networks with $\mathrm{R}=0.5$ as the example.

Creep-recovery behavior and thermodilatometry of $\mathrm{ESO} / \mathrm{GL}$ networks $(\mathrm{R}=0.5$, TBD $5 \mathrm{~mol} \%)$ were also investigated for verifying further TERs. As shown in the Figure 3d, the material flowed after an initial elastic response at $200^{\circ} \mathrm{C}$, due to the TERs. The strain increased to $10.5 \%$ until the stress was revoked after $60 \mathrm{~min}$. Then, the strain decreased slightly and retained $7.1 \%$ of elongation in the remaining time. Furthermore, its malleability temperature $\left(T_{\text {mall }}\right)$ was measured using DMA with controlled force model as shown in Figure S9. A notable increase in the expansion coefficient appeared at the temperature above $138^{\circ} \mathrm{C}$, defined as $T_{\text {mall }} .{ }^{14,53}$ After this temperature, the strain increased drastically with temperature because of the accelerated transesterification rate, and the material became malleable driven by the topological network rearrangements.

Welding, repairing, and shape changing properties. The TERs-induced stress relaxation imparted multi-functionalities to materials such as welding, repairing, and shape changing. To 
study welding properties three pieces of $\mathrm{ESO} / \mathrm{GL}(\mathrm{R}=0.5$, TBD $5 \mathrm{~mol} \%)$ materials were selected to make up an " $\mathrm{H}$ " pattern as shown in Figure $4 \mathrm{a}$, and the welding was proceeded at $200^{\circ} \mathrm{C}$ for only 15 min without pressure. After the network rearrangements, an integral material was produced and could bear nearly $100 \mathrm{~g}$ weight which was 300 times heavier than itself (Figure 4b), highlighting the good weldability.

For repairing properties, a piece of sample was scratched to have a crack on the surface, and then was heated at $200^{\circ} \mathrm{C}$ in an oven. As shown in Figure 4c, the width of the crack decreased from 100 to $19 \mu \mathrm{m}$ within $5 \mathrm{~min}$ and eventually disappeared after $60 \mathrm{~min}$, exhibiting the repairing ability. The similar repairing results were also obtained for $\mathrm{R}=0.4$ and 0.6 , which indicated the quick rate of TERs in ESO/GL networks (Figure S10).

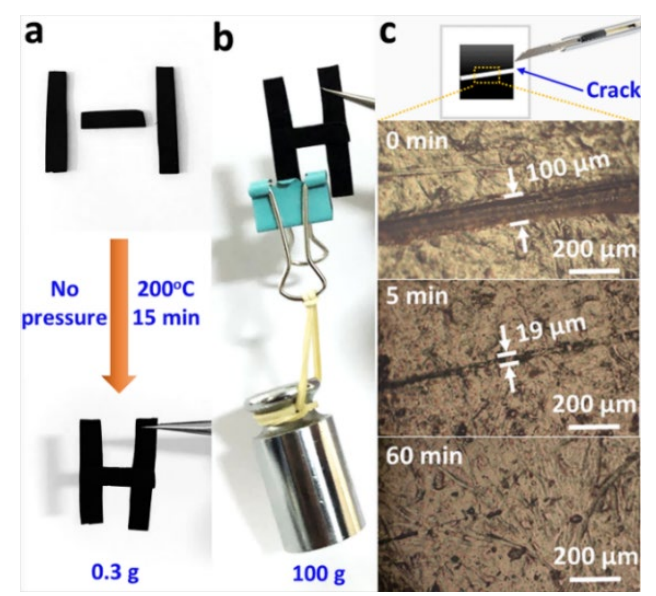

Figure 4. (a) and (b) Welding test of ESO/GL networks (R =0.5, TBD $5 \mathrm{~mol} \%$ ). (c) Optical microscope images of the crack repairation of ESO/GL networks $(\mathrm{R}=0.5$, TBD $5 \mathrm{~mol} \%)$ at $200^{\circ} \mathrm{C}$.

Note that for the ESO/GL networks $(\mathrm{R}=0.5$, TBD $5 \mathrm{~mol} \%$ ), there were four characteristic temperatures: $T_{g(\mathrm{DMA})}=49^{\circ} \mathrm{C}, T_{v}=69^{\circ} \mathrm{C}, T_{\text {mall }}=138^{\circ} \mathrm{C}$ and $T_{d 5}=328^{\circ} \mathrm{C}$. Figure 5a showed its deformation-time curves for temperature range from 0 to $60^{\circ} \mathrm{C}$ to evaluate the consecutive shape memory around the glass transition $\left(T_{g}\right)$, where all curves were normalized according to the 
maximum deformation at the first cycle for a better comparison. The shape fixity $\left(R_{f}\right)$ and shape recovery $\left(R_{r}\right)$ were defined as the following equations:

$$
\begin{gathered}
R_{f}=\frac{\varepsilon_{d}}{\varepsilon_{\text {load }}} \times 100 \% \\
R_{r}=\frac{\varepsilon_{d}-\varepsilon_{r e c}}{\varepsilon_{d}} \times 100 \%
\end{gathered}
$$

where $\varepsilon_{\text {load }}$ represents the maximum deformation under load, $\varepsilon_{d}$ is the fixed deformation after cooling and load removal, and $\varepsilon_{r e c}$ is the recovered deformation. The calculated $R_{f}$ and $R_{r}$ values for each cycle were listed in Table 2 . The value of $R_{f}$ was approximately $92 \%$ for all three cycles, and such good dimensional stability was attributed to the rigid backbone of GL within the networks. In addition, the value of $R_{r}$ was higher than $94 \%$ in each cycle which revealed that $\mathrm{ESO} / \mathrm{GL}$ networks $(\mathrm{R}=0.5$, TBD $5 \mathrm{~mol} \%)$ had a great shape memory property.
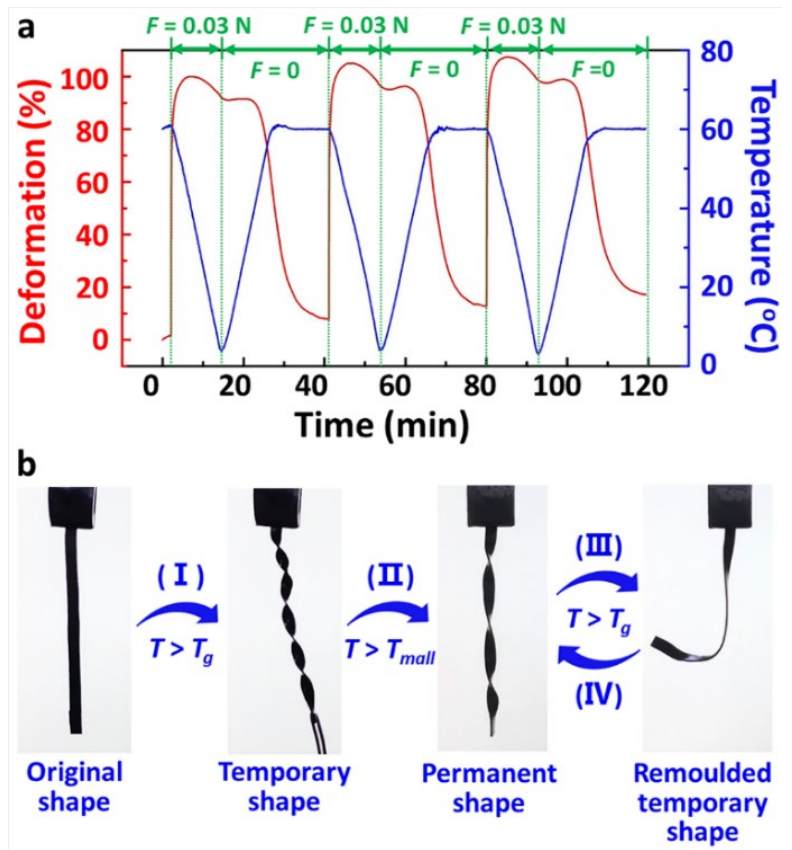

Figure 5. (a) Consecutive shape memory cycles for ESO/GL networks ( $\mathrm{R}=0.5$, TBD $5 \mathrm{~mol} \%$ ) using DMA tensile model. Sample size: $30 \mathrm{~mm} \times 5 \mathrm{~mm} \times 1 \mathrm{~mm}$. (b) Pictures of temporary shape changing and permanent shape changing of $\mathrm{ESO} / \mathrm{GL}$ networks $(\mathrm{R}=0.5$, TBD $5 \mathrm{~mol} \%)$. (I): Deformation using a tweezer at temperature above $T_{g}$ for $10 \mathrm{~s}$. The temporary shape was fixed 
after cooling to room temperature (RT). (II): Fixation of the twisted shape by heating above $T_{\text {mall }}$ for $10 \mathrm{~min}$ through stress relaxation with TERs. The permanent deformation was obtained when cooling to RT. (III): The permanent shape could be remoulded into another temporary shape at $T>$ $T_{g}$ for $10 \mathrm{~s}$ and kept when cooling to RT. (IV): The permanent shape was recovered when heating above $T_{g}$ for $10 \mathrm{~s}$.

Table 2. Values of shape fixity $\left(R_{f}\right)$ and shape recovery $\left(R_{r}\right)$ for $\mathrm{ESO} / \mathrm{GL}$ networks $(\mathrm{R}=0.5$, TBD $5 \mathrm{~mol} \%)$.

\begin{tabular}{cccccc}
\hline \multicolumn{3}{c}{$R_{f}(\%)$} & \multicolumn{3}{c}{$R_{r}(\%)$} \\
\hline cycle 1 & cycle 2 & cycle 3 & cycle 1 & cycle 2 & cycle 3 \\
92.9 & 92.7 & 91.8 & 94.8 & 94.1 & 95.4 \\
\hline
\end{tabular}

Figure $5 \mathrm{~b}$ and Movie $\mathrm{S} 1$ demonstrated the direct visualization of the vitrimer reprocessing and shape memory. Initially, the flat ribbon of ESO/GL networks $(\mathrm{R}=0.5$, TBD $5 \mathrm{~mol} \%)$ was heated above $T_{g}$ for $10 \mathrm{~s}$ to deform a twisted ribbon fixed by using a tweezer (Process I). Subsequently, the twisted ribbon was heated above $T_{\text {mall }}$ for 10 min using a blower, which made stresses relax due to the topological network rearrangements. After cooling to room temperature the permanent twisted ribbon was obtained (Process II). This permanent twisted ribbon shape could not recover to the original flat shape because of the "plasticity deformation" by TERs. ${ }^{11,12,54}$ Furthermore, it could be fixed to another "temporary form" and recovered using heating-cooling process at a temperature above $T_{g}$. As shown in Figure 5b (Process III), the twisted ribbon was heated above $T_{g}$ for $10 \mathrm{~s}$ and deformed to a temporary form "J". Finally, the "J" recovered to the twisted ribbon again after heating above $T_{g}$ for $10 \mathrm{~s}$ (Process IV). In this cycle (Process III and IV), the external stress was applied when the mobility of chain segments was activated above $T_{g}$ to get a macroscopic deformation. Such a deformation can be temporarily fixed by decreasing the chain 
mobility through cooling, while re-activating the chain segments by heating led to a shape recovery driven by the stored entropic energy. Obviously, the permanent deformation and shape memory properties allow the design of 3D structures from our biobased ESO/GL vitrimers. Furthermore, as $T_{g}$ of ESO/GL networks ( $\mathrm{R}=0.5$, TBD $5 \mathrm{~mol} \%$ ) was close to apparent temperature of human beings, we tried to achieve the shape changing and recovery of ESO/GL vitrimer on hands instead of using heating stage or oven. As shown in Movie S2, the shape of flat film was changed by apparent temperature and fixed easily at room temperature. Also, it just took $100 \mathrm{~s}$ to recover the original flat shape upon heating by hands (Movie S3). Since the shape memory property of $\mathrm{ESO} / \mathrm{GL}$ vitrimers $(\mathrm{R}=0.5$, TBD $5 \mathrm{~mol} \%)$ only depended on apparent temperature of hands, we called it "apparent temperature shape memory, ATSM", which may have the potential application in wearable soft devices.

Recycling and lap-shear properties. After confirming the malleability of the TERs-based $\mathrm{ESO} / \mathrm{GL}$ networks $(\mathrm{R}=0.5$, TBD $5 \mathrm{~mol} \%$ ), we evaluated their recyclability. The physical recycle process was shown in Figure 6a. The original samples were initially broken into pieces, and then were re-filled into a mound. After hot press at $200^{\circ} \mathrm{C}$, these pieces were fully recycled to form integral samples. Figure $6 \mathrm{~b}$ showed the representative stress-strain curves before and after recycling. The tensile strength reduced from 3.1 to $1.4 \mathrm{MPa}$ with a recycle efficiency of $\sim 45 \%$, and the decrease in tensile strength was mainly due to: 1) the breakage of partial permanent linkages between hydroxyl groups with ESO, 2) the oxidation of trace diglucuronic units on GL, and 3) the interfacial defects in recycled vitrimers (Figure S11). Conversely, the tensile modulus of recycled material maintained $2366 \mathrm{MPa}$ in comparison with $2483 \mathrm{MPa}$ of the original one. The high recycle efficiency in tensile modulus $(\sim 95 \%)$ indicated that the holistic chemical structure of 
networks hardly changed after the recycle process, with keeping the similar molecular weight and rigidness of vitrimer networks.
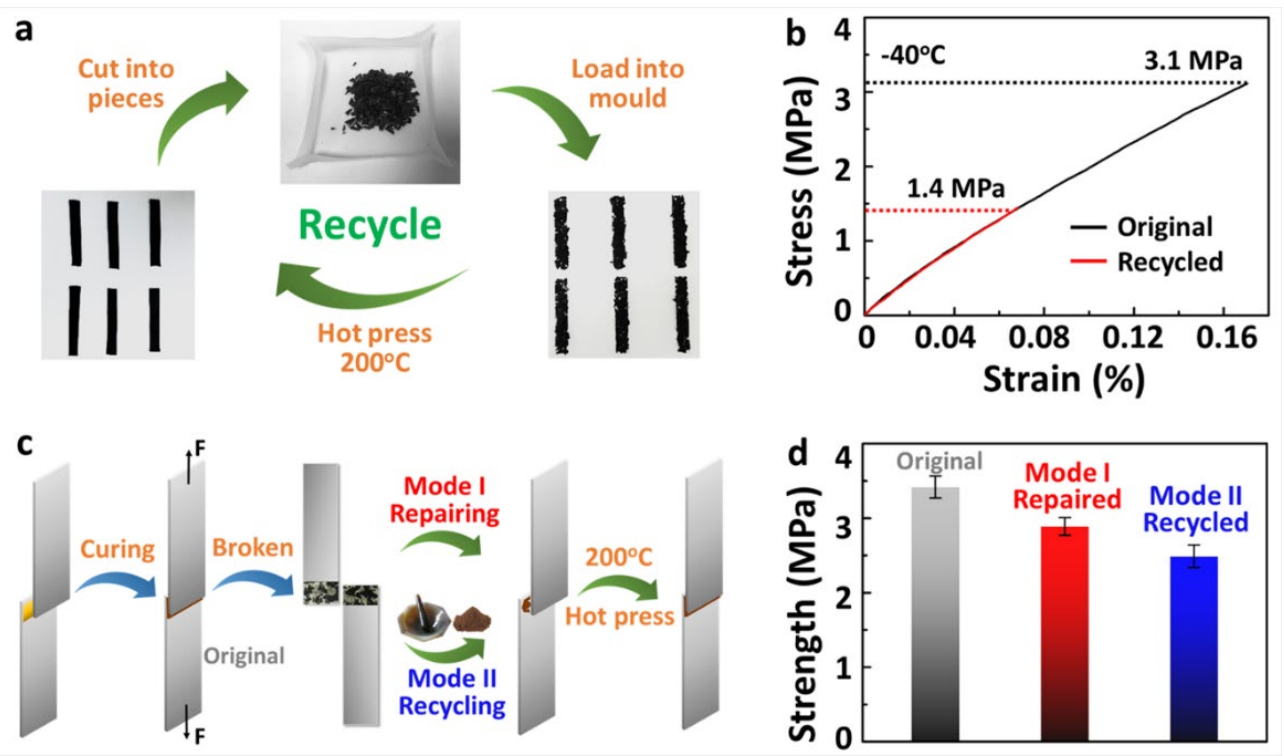

Figure 6. (a) Photos showing the recycling process of ESO/GL networks ( $\mathrm{R}=0.5$, TBD 5 mol\%); (b) Stress-strain curves of ESO/GL networks $(\mathrm{R}=0.5$, TBD $5 \mathrm{~mol} \%)$ at $-40^{\circ} \mathrm{C}$ before and after recycling. Low temperature ensured that the measurement was performed at glass plateau. (c) Schematic view of lap-shear tests for ESO/GL networks $(\mathrm{R}=0.5$, TBD 5 mol\%), repaired (Mode I) and recycled (Mode II) samples. (d) Lap-shear strength of original, repaired and recycled samples.

Having the repairing and recycling properties of $\mathrm{ESO} / \mathrm{GL}$ networks $(\mathrm{R}=0.5$, TBD $5 \mathrm{~mol} \%)$ in hands, its application as adhesive was investigated using lap-shear test. Adhesion samples were prepared by bonding two aluminum sheets with uncured ESO/GL $(\mathrm{R}=0.5$, TBD $5 \mathrm{~mol} \%)$ as shown in Figure 6c. The bonding area was $12.5 \mathrm{~mm} \times 25 \mathrm{~mm}$ and the thickness of the interval was $0.2 \mathrm{~mm}$. After curing, two aluminum sheets were bonded together successfully (original adhesive) and the lap-shear strength was measured to $3.42 \mathrm{MPa}$ (Figure 6d). Unlike traditional epoxy adhesives the network of ESO/GL adhesive can be topologically rearranged due to the TERs. 
Therefore, the failed two halves of adhesive were facilely re-bonded together using hot press at $200^{\circ} \mathrm{C}$ (Mode I, repaired adhesive, Figure 6c) with a lap-shear strength $2.89 \mathrm{MPa}$ (Figure 6d). Notably, after the tests the adhesive can be found on both halves of aluminum sheets for original and repaired ones (Figure S12), which meant that the lap-shear damage was caused by cohesive failure, not adhesive failure between aluminum and adhesive interfaces. In addition, the redundant cured $\mathrm{ESO} / \mathrm{GL}(\mathrm{R}=0.5$, TBD $5 \mathrm{~mol} \%)$ grinded into powder could also be employed as adhesive (Mode II, recycled adhesive, Figure 6c) with a lap-shear strength 2.49 MPa (Figure 6d). However, for the recycled adhesive sample the lap-shear damage was mainly caused by adhesive failure (Figure S12), probably because the cured ESO/GL powder could not contact with aluminum surface as well as the uncured one. It was worth noting that the biobased ESO/GL adhesive had comparable properties with those of biobased adhesives and of some commercial adhesives (Table S1). Moreover, this is the first report on the recyclability of biobased adhesives. ${ }^{10,24}$

Chemical degradability and cell viability. In practice, materials need to be degraded when they could not maintain their useful properties. The chemical degradability of ESO/GL networks $(\mathrm{R}=$ 0.5 , TBD $5 \mathrm{~mol} \%)$ was investigated at high temperature $\left(180^{\circ} \mathrm{C}\right)$ by using ethylene glycol (EG) as the reactant and solvent. As shown in Figure 7a, the square sample became smaller and irregular in shape, and the EG solution changed from transparent to brown after $14 \mathrm{~h}$. The relative weight as a function of degradation time was shown in Figure $7 \mathrm{~b}$, where the weight decreased rapidly to $30 \%$ within the first $6 \mathrm{~h}$, then decreased slowly to $7 \%$ until $12 \mathrm{~h}$, and finally stabilized until $14 \mathrm{~h}$. Apparently, the hydroxyl groups of EG participated in TERs of ESO/GL networks at $180^{\circ} \mathrm{C}$, thus causing the network degradation as shown in Figure 7c. ${ }^{55,56}$ Notably, the residual of sample (7\%) was mainly due to partial permanent linkages offered by hydroxyl-epoxy reactions during curing process. 
The biocompatibility of ESO/GL vitrimer ( $\mathrm{R}=0.5$, TBD $5 \mathrm{~mol} \%$ ) was evaluated by the cell culture experiment of fibroblasts NIH-3T3 in the presence of the vitrimer. As shown in Figure 7d, dead cells were stained in red and live cells in green. Cell images showed that the majority of fibroblasts NIH-3T3 still survived in the presence of vitrimer for $24 \mathrm{~h}$. Due to its outstanding biocompatibility and natural origin, the ESO/GL vitrimer may find potential application in biorelated fields.
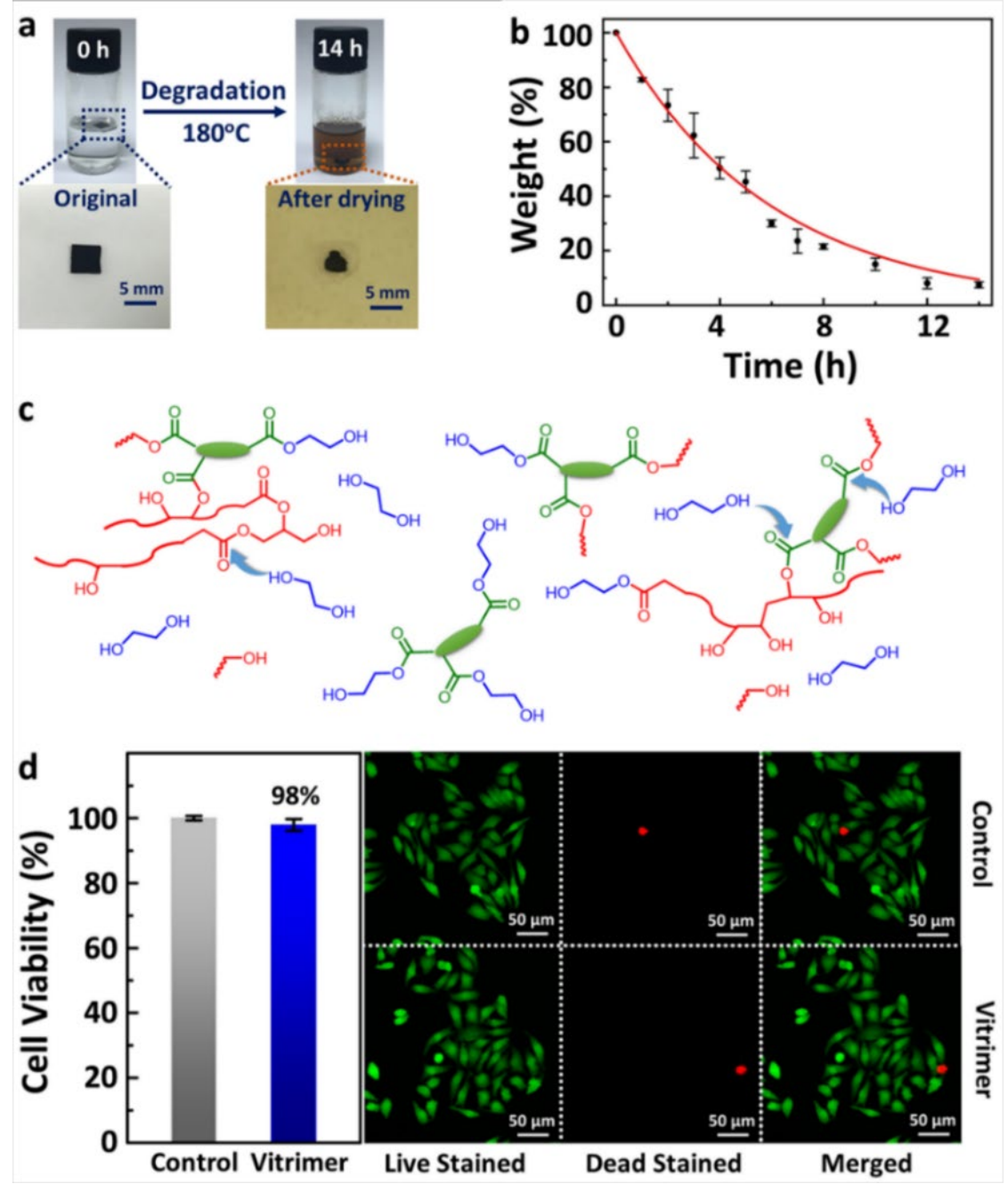

Figure 7. (a) Photo showing the chemical degradation experiment. (b) The weight loss of ESO/GL $(\mathrm{R}=0.5$, TBD $5 \mathrm{~mol} \%)$ networks as a function of degradation time. The red line is the fit with the exponential decay function $m_{t}=m_{0} e^{-t / \tau}$, where $m_{t} / m_{0}$ is the relative weight and $\tau(5.9 \mathrm{~h})$ is the 
characteristic time when $m_{t}$ decreases to $36.8 \%$ of $m_{0}$. (c) Mechanism of chemical degradation of $\mathrm{ESO} / \mathrm{GL}$ networks ( $\mathrm{R}=0.5$, TBD $5 \mathrm{~mol} \%$ ) at $180^{\circ} \mathrm{C}$ in the presence of $\mathrm{EG}$. (d) Cell viability and cell images after the treatment with ESO/GL networks ( $\mathrm{R}=0.5$, TBD $5 \mathrm{~mol} \%$ ) for $24 \mathrm{~h}$.

\section{CONCLUSIONS}

In this work, fully biobased vitrimers contained $100 \%$ renewable carbon content were developed by using direct reaction between epoxidised soybean oil (ESO) and natural glycyrrhizic acid (GL) without any additional chemical modification. All vitrimers had the 3D crosslinked networks with good thermal stability, and their $T_{g}$ evaluated by DMA ranged from 39 to $64^{\circ} \mathrm{C}$ depending on the molar ratios between ESO and GL. The stress relaxation, creep-recovery, and thermodilatometry measurements revealed an effective transesterification exchanged reactions (TERs) within the networks at elevated temperature (e.g., $200^{\circ} \mathrm{C}$ ). These vitrimers showed good welding, repairing, and shape changing properties. Due to the unique rigid skeleton of GL, ESO/GL vitrimers owned great thermal stability and mechanical properties. The lap-shear strength of 3.42, 2.89 and 2.49 MPa were detected for original, repaired and recycled samples of ESO/GL, demonstrating that this vitrimer can be applied as repairable and recyclable adhesives. Furthermore, the vitrimer could be degraded effectively by ethylene glycol, and exhibited excellent biocompatibility. Our fully biobased multifunctional vitrimers enrich the library of biobased vitrimers and thermosets.

\section{ASSOCIATED CONTENT}

\section{Supporting Information.}

The following files are available free of charge.

Characterization; reaction mechanism of ESO with GL; ${ }^{1} \mathrm{H}$ NMR spectrum of epoxidised soybean oil; preparation of ESO/GL networks; curing reactivity study using a control system ESO/GA; thermal stability of TBD and $\mathrm{ESO} / \mathrm{GL} / \mathrm{TBD}$ mixture before the curing reactions; the possible 
transition structure of TBD with carboxyl groups of GL; FTIR spectra analysis for curing reactions; thermal stability of ESO/GL networks; chemical structure of carbenoxolone (CBX) and photo of cured $\mathrm{ESO} / \mathrm{CBX}$ material; topology freezing transition temperature of $\mathrm{ESO} / \mathrm{GL}$ networks; thermodilatometry testing of ESO/GL networks; repairing tests of ESO/GL networks; apparent temperature shape memory of ESO/GL; tensile tests for original and recycled samples; photos of samples after lap-shear tests and the comparison between this work and other adhesives; Movie S1; Movie S2; Movie S3.

\section{Notes}

The authors declare no competing financial interest.

\section{ACKNOWLEDGMENT}

This work is supported by NSFC (no. 21604085) and National Key R\&D Program of China (no. 2017YFD0200302).

\section{REFERENCES}

(1) Billmeyer, F. W. Textbook of Polymer Science, Wiley, New York, ed., 1984.

(2) Pascault, J. P.; Williams, R. J. J.; Verdu, J.; Sautereau, H. Thermosetting Polymers, John Wiley \& Sons, Inc. 2013.

(3) Jin, F. L.; Li, X.; Park, J. S. Synthesis and application of epoxy resins: A review. J. Ind. Eng. Chem. 2015, 29, 1-11, DOI 10.1016/j.jiec.2015.03.026.

(4) Ghosh, N. N.; Kiskan, B.; Yagci, Y. Polybenzoxazines-New high performance thermosetting resins: synthesis and properties. Prog. Polym. Sci. 2007, 32, 1344-1391, DOI 10.1016/j.progpolymsci.2007.07.002. 
(5) Montarnal, D.; Capelot, M.; Tournilhac, F.; Leibler, L. Silica like malleable materials from permanent organic networks. Science 2011, 334, 965-968, DOI 10.1126/science.1212648.

(6) Capelot, M.; Montarnal, D.; Tournilhac, F.; Leibler, L. Metal catalyzed transesterification for healing and assembling of thermosets. J. Am. Chem. Soc. 2012, 134, 7664-7667, DOI $10.1021 / \mathrm{ja} 302894 \mathrm{k}$.

(7) Capelot, M.; Unterlass, M. M.; Tournilhac, F.; Leibler L.; Catalytic control of the vitrimer glass transition. ACS Macro Lett. 2012, 1, 789-792, DOI 10.1021/mz300239f.

(8) Denissen, W.; Winne, J. M.; Prez, F. E. D. Vitrimers: Permanent organic networks with glasslike fluidity. Chem. Sci. 2016, 7, 30-38, DOI 10.1039/c5sc02223a.

(9) Röttger, M.; Domenech, T.; Weegen, R. van der, Breuillac, A.; Nicolaÿ, R.; Leibler, L. High-performance vitrimers from commodity thermoplastics through dioxaborolane metathesis. Science 2017, 356, 62-65, DOI 10.1126/science.aah5281.

(10) Tang, J.; Wan, L.; Zhou, Y.; Pan, H.; Huang, F. Strong and efficient self-healing adhesives based on dynamic quaternization cross-links. J. Mater. Chem. A 2017, 5, 21169-21177, DOI $10.1039 / \mathrm{c} 7 \mathrm{ta} 06650 \mathrm{c}$.

(11) Zhao, Q.; Zou, W.; Luo, Y.; Xie, T. Shape memory polymer network with thermally distinct elasticity and plasticity. Sci. Adv. 2016, 2, e1501297, DOI 10.1126/sciadv.1501297.

(12) Zheng, N.; Fang, Z.; Zou, W.; Zhao, Q. Xie, T. Thermoset shape-memory polyurethane with intrinsic plasticity enabled by transcarbamoylation. Angew. Chem. Int. Ed. 2016, 55, 11421-11425, DOI 10.1002/anie.201602847. 
(13) Fang, Z.; Zheng, N.; Zhao, Q.; Xie, T. Healable, reconfigurable, reprocessable thermoset shape memory polymer with highly tunable topological rearrangement kinetics. ACS Appl. Mater. Inter. 2017, 9, 22077-22082, DOI 10.1021/acsami.7b05713.

(14) Pei, Z.; Yang, Y.; Chen, Q.; Terentjev, E. M.; Wei, Y.; Ji, Y. Mouldable liquid-crystalline elastomer actuators with exchangeable covalent bonds. Nat. Mater. 2014, 13, 36-41, DOI 10.1038/nmat3812.

(15) Pei, Z.; Yang, Y.; Chen, Q.; Wei, Y.; Ji, Y. Regional Shape Control of Strategically assembled multishape memory vitrimers. Adv. Mater. 2016, 28, 156-160, DOI 10.1002/adma.201503789.

(16) Yang, Y.; Pei, Z.; Li, Z.; Wei, Y.; Ji, Y. Making and remaking dynamic 3D structures by shining light on flat liquid crystalline vitrimer films without a mold. J. Am. Chem. Soc. 2016, 138, 2118-2121, DOI 10.1021/jacs.5b12531.

(17) Lu, X.; Guo, S.; Tong, X.; Xia, H.; Zhao, Y. Tunable photocontrolled motions using stored strain energy in malleable azobenzene liquid crystalline polymer actuators. Adv. Mater. 2017, 29, 1606467, DOI 10.1002/adma.201606467.

(18) Shi, Q.; Yu, K.; Kuang, X.; Mu, X.; Dunn, C. K.; Dunn, M. L.; Wang, T.; Qi, H. J. Recyclable 3D printing of vitrimer epoxy. Mater. Horiz. 2017, 4, 598-607, DOI 10.1039/c7mh00043j.

(19) Zhang, B.; Kowsari, K.; Serjouei, A.; Dunn, M. L.; Ge, Q. Reprocessable thermosets for sustainable three-dimensional printing. Nat. Commun. 2018, 9, 1831, DOI $10.1038 / \mathrm{s} 41467-018-04292-8$. 
(20) Gandini, A.; Lacerda, T. M.; Carvalho, A. J. F.; Trovatti, E. Progress of polymers from renewable resources: Furans, vegetable oils, and polysaccharides. Chem. Rev. 2016, 116, 1637-1669, DOI 10.1021/acs.chemrev.5b00264.

(21) Zhu, Y.; Romain, C.; Williams, C. K. Sustainable polymers from renewable resources. Nature 2016, 540, 354-362, DOI 10.1038/nature21001.

(22) Altuna, F. I.; Pettarin, V.; Williams, R. J. J. Self-healable polymer networks based on the crosslinking of epoxidised soybean oil by an aqueous citric acid solution. Green Chem. 2013, 15, 3360-3366, DOI 10.1039/c3gc41384e.

(23) Liu, T.; Hao, C.; Wang, L.; Li, Y.; Liu, W.; Xin, J.; Zhang, J. Eugenol-derived biobased epoxy: shape memory, repairing, and recyclability. Macromolecules 2017, 50, 8588-8597, DOI 10.1021/acs.macromol.7b01889.

(24) Zhang, S.; Liu, T.; Hao, C.; Wang, L.; Han, J.; Liu, H.; Zhang, J. Preparation of a ligninbased vitrimer material and its potential use for recoverable adhesives. Green Chem. 2018, 20, 2995-3000, DOI 10.1039/c8gc01299g.

(25) Liu, T.; Hao, C.; Zhang, S.; Yang, X.; Wang, L.; Han, J.; Li, Y.; Xin, J.; Zhang, J. A selfhealable high glass transition temperature bioepoxy material based on vitrimer chemistry. Macromolecules 2018, 51, 5577-5585, DOI 10.1021/acs.macromol.8b01010.

(26) Wang, S.; Ma, S. Li, Q.; Yuan, W.; Wang, B.; Zhu, J. Robust, Fire-safe, monomer-recovery, highly malleable thermosets from renewable bioresources. Macromolecules 2018, 51, 8001-8012, DOI 10.1021/acs.macromol.8b01601. 
(27) Wang, S.; Ma, S.; Li, Q.; Xu, X.; Wang, B.; Yuan, W.; Zhou, S.; You, S.; Zhu, J. Facile in situ preparation of high-performance epoxy vitrimer from renewable resources and its application in nondestructive recyclable carbon fiber composite. Green Chem. 2019, 21, 1484-1497, DOI: $10.1039 / \mathrm{c} 8 \mathrm{gc} 03477 \mathrm{j}$.

(28) Ma, S.; Wei, J.; Jia, Z.; Yu, T.; Yuan, W.; Li, Q.; Wang, S.; You, S.; Liu, R.; Zhu, J. Readily recyclable, high-performance thermosetting materials based on a lignin-derived spiro diacetal trigger. J. Mater. Chem. A 2019, 7, 1233-1243, DOI 10.1039/c8ta07140c.

(29) Geng, H.; Wang, Y.; Yu, Q.; Gu, S.; Zhou, Y.; Xu, W.; Zhang, X. Ye, D. Vanillin-based polyschiff vitrimers: Reprocessability and chemical recyclability. ACS Sustain. Chem. Eng. 2018, 6, 15463-15470, DOI 10.1021/acssuschemeng.8b03925.

(30) Dhers, S.; Vantomme, G.; Avérous, L. Fully bio-based polyimine vitrimer derived from fructose. Green Chem. 2019, 21, 1596-1601, DOI 10.1039/C9GC00540D.

(31) Li, M. H.; Brûlet, A.; Keller, P.; Strazielle, C.; Cotton, J. P. Study of the transesterification of a main-chain mesomorphic polyester by small-angle neutron scattering. Macromolecules 1993, 26, 119-124, DOI 10.1021/ma00053a019.

(32) Ploeger, B.; Mensinga, T.; Sips, A.; Seinen, W.; Meulenbelt, J.; DeJongh, J. The pharmacokinetics of glycyrrhizic acid evaluated by physiologically based pharmacokinetic modeling. Drug Metab. Rev. 2001, 33, 125-147, DOI 10.1081/DMR-100104400.

(33) Kornievskaya, V. S.; Kruppa, A. I.; Leshina, T. V. NMR and photo-CIDNP investigations of the glycyrrhizinic acid micelles influence on solubilized molecules. J. Inclusion Phenom. Macrocyclic Chem. 2007, 60, 123-130, DOI 10.1007/s10847-007-9360-x. 
(34) Tykarska, E.; Sobiak, S.; Gdaniec, M. Supramolecular organization of neutral and ionic forms of pharmaceutically relevant glycyrrhizic acid-amphiphile self-assembly and inclusion of small drug molecules. Cryst. Growth Des. 2012, 12, 2133-2137, DOI $10.1021 / \operatorname{cg} 300160 \mathrm{c}$.

(35) Han, S.; Sun, L.; He, F.; Che, H. Anti-allergic activity of glycyrrhizic acid on IgE-mediated allergic reaction by regulation of allergyrelated immune cells. Sci. Rep. 2017, 7, 7222, DOI 10.1038/s41598-017-07833-1.

(36) Saha, A.; Adamcik, J.; Bolisetty, S.; Handschin, S.; Mezzenga, R. Fibrillar networks of glycyrrhizic acid for hybrid nanomaterials with catalytic features. Angew. Chem. Int. Ed. 2015, 54, 5408-5412, DOI 10.1002/anie.201411875.

(37) Ma, L.; Wan, Z.; Yang, X. Multiple water-in-oil-in-water emulsion gels based on selfassembled saponin fibrillar network for photosensitive cargo protection. J. Agric. Food Chem. 2017, 65, 9735-9743, DOI 10.1021/acs.jafc.7b04042.

(38) Wan, Z.; Sun, Y.; Ma, L.; Guo, J.; Wang, J. Yin, S.; Yang, X. Thermoresponsive structured emulsions based on the fibrillar self-assembly of natural saponin glycyrrhizic acid. Food Funct. 2017, 8, 75-85, DOI 10.1039/C6FO01485B.

(39) Ma, Y.; Gao, Y.; Zhao, X.; Zhu, Y.; Du, F.; Hu, J. A natural triterpene saponin-based pickering emulsion. Chem. Eur. J. 2018, 24, 11703-11710, DOI 10.1002/chem.201801619.

(40) Han, J.; Liu, T.; Hao, C.; Zhang, S.; Guo, B.; Zhang, J. A catalyst-free epoxy vitrimer system based on multifunctional hyperbranched polymer. Macromolecules 2018, 51, 67896799, DOI 10.1021/acs.macromol.8b01424. 
(41) Ratna, D. Mechanical properties and morphology of epoxidized soyabean-oil-modified epoxy resin. Polym. Int. 2001, 50, 179-184, DOI 10.1002/10970126(200102)50:2<179::AID-PI603>3.0.CO;2-E.

(42) Wang, X. L.; Chen, L.; Wu, J. N.; Fu, T.; Wang, Y. Z. Flame-retardant pressure-sensitive adhesives derived from epoxidized soybean oil and phosphorus-containing dicarboxylic acids. ACS Sustain. Chem. Eng. 2017, 5, 3353-3361, DOI 10.1021/acssuschemeng.6b03201.

(43) Gerbase, A. E.; Petzhold, C. L.; Costa, A. P. O. Dynamic mechanical and thermal behavior of epoxy resins based on soybean oil. J. Am. Oil Chem. Soc. 2002, 79, 797-802, DOI 10.1007/s11746-002-0561-z.

(44) Qi, M.; Xu, Y.; Rao, W.; Luo, X.; Chen, L.; Wang, Y. Epoxidized soybean oil cured with tannic acid for fully bio-based epoxy resin. RSC $A d v . \mathbf{2 0 1 8}, 8,26948-26958$, DOI $10.1039 / \mathrm{c} 8 \mathrm{ra} 03874 \mathrm{k}$.

(45) Zeng, C.; Hu, Q. Determination of the polyacid dissociation constants of glycyrrhizic acid. Indian J. Chem. 2008, 47A, 71-74.

(46) Binkowska, I.; Jarczewski, A.; Katrusiak, A.; Wojciechowski, G.; Brzezinski, B. Structural and spectroscopic studies of the 1:1 complex of 4-nitrophenyl[bis(ethylsulfonyl)]methane1,5,7-triazabicyclo[4.4.0]dec-5-ene. $\quad J . \quad$ Mol. Struct. 2001, 597, 101-107, DOI $10.1016 / \mathrm{S} 0022-2860(01) 00581-6$.

(47) Ng, S. W.; Naumov, P.; Chantrapromma, S.; Raj, S. S. S.; Fun, H. Ibrahim, A. R.; Wojciechowski, G.; Brzezinski, B. Structural and spectroscopic studies of the 1:2 complex 
of 1,5,7-triazabicyclo[4.4.0]dec-5-ene-4-nitrophenyl. J. Mol. Struct. 2001, 562, 185-196, DOI 10.1016/S0022-2860(00)00926-1.

(48) Huczyński, A.; Binkowska, I.; Jarczewski, A.; Brzezinski, B. Spectroscopic studies of the 1:1 complexes of 4-nitrophenyl[bis(ethylsulfonyl)]methane and phenyl[bis(ethylsulfonyl)]methane with 7-methyl-1,5,7-triazabicyclo[4.4.0]dec-5-ene and 1,5,7-triazabicyclo[4.4.0]dec-5-ene. $\quad J . \quad$ Mol. Struct. 2007, 841, 133-136, DOI 10.1016/j.molstruc.2007.01.005.

(49) Yu, K.; Taynton, P.; Zhang, W.; Dunnc, M. L.; Qi, H. J. Influence of stoichiometry on the glass transition and bond exchange reactions in epoxy thermoset polymers. RSC Adv. 2014, 4, 48682-48690, DOI 10.1039/c4ra06543c.

(50) Brutman, J. P.; Delgado, P. A.; Hillmyer, M. A. Polylactide Vitrimers. ACS Macro Lett. 2014, 3, 607-610, DOI 10.1021/mz500269w.

(51) Chen, Q.; Li, Y.; Yang, Y.; Xu, Y.; Qian, X.; Wei, Y.; Ji, Y. Durable liquid-crystalline vitrimer actuators. Chem. Sci. 2019, 10, 3025-3030, DOI 10.1039/c8sc05358h.

(52) Snyder, R. L.; Fortman, D. J.; Hoe, G. X. D.; Hillmyer, M. A.; Dichtel, W. R. Reprocessable acid-degradable polycarbonate vitrimers. Macromolecules 2018, 51, 389397, DOI 10.1021/acs.macromol.7b02299.

(53) Chen, M.; Zhou, L.; Wu, Y.; Zhao, X.; Zhang, Y. Rapid stress relaxation and moderate temperature of malleability enabled by the synergy of disulfide metathesis and carboxylate transesterification in epoxy vitrimers. ACS Macro Lett. 2019, 8, 255-260, DOI 10.1021/acsmacrolett.9b00015. 
(54) Zou, W.; Dong, J.; Luo, Y.; Zhao, Q.; Xie, T. Dynamic covalent polymer networks: from old chemistry to modern day innovations. Adv. Mater. 2017, 29, 1606100, DOI 10.1002/adma.201606100.

(55) Yu, K.; Shi, Q.; Dunn, M. L.; Wang, T.; Qi, H. J. Carbon fiber reinforced thermoset composite with near $100 \%$ recyclability. Adv. Funct. Mater. 2016, 26, 6098-6106, DOI 10.1002/adfm.201602056.

(56) Kuang, X.; Shi, Q.; Zhou, Y.; Zhao, Z.; Wang, T.; Qi, H. J. Dissolution of epoxy thermosets via mild alcoholysis: the mechanism and kinetics study. $R S C A d v . \mathbf{2 0 1 8}, 8,1493-1502$, DOI $10.1039 / \mathrm{c} 7 \mathrm{ra} 12787 \mathrm{a}$. 


\section{For Table of Contents Use Only}

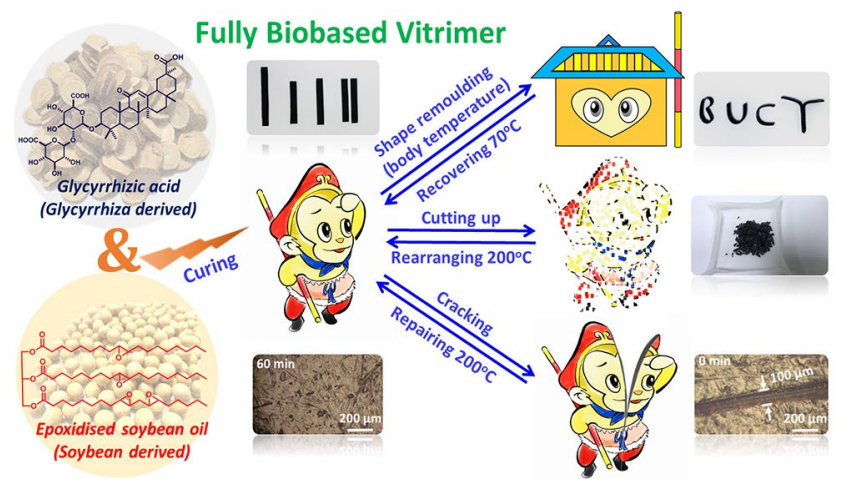

Fully biobased vitrimers have been prepared by using natural glycyrrhizic acid and epoxidised soybean oil as raw materials without any chemical modification. 


\title{
Supporting Information
}

\section{Fully Biobased Vitrimers from Glycyrrhizic Acid and Soybean Oil for Self-Healing, Shape Memory, Weldable and Recyclable Materials}

\author{
Jianqiao Wu, ${ }^{\dagger}$ Xia Yu, ${ }^{\dagger}$ Hao Zhang, ${ }^{\dagger}$ Junbo Guo, ${ }^{\dagger}$ Jun Hu, ${ }^{* \dagger}$ Min-Hui Li, ${ }^{*}+\neq$
}

$\dagger$ Beijing Advanced Innovation Center for Soft Matter Science and Engineering, Beijing University of Chemical Technology, North Third Ring Road 15, Chaoyang District, Beijing 100029, China.

Institut de Recherche de Chimie Paris, Chimie ParisTech, PSL Research University, CNRS, 11 rue Pierre et Marie Curie, Paris 75005, France.

\section{*Corresponding Authors}

Email: jhu@mail.buct.edu.cn (Jun Hu);

min-hui.li@chimieparistech.psl.eu (Min-Hui Li).

The supporting information includes 13 pages, 12 figures, 1 table and 2 schemes. 


\section{Table of Contents}

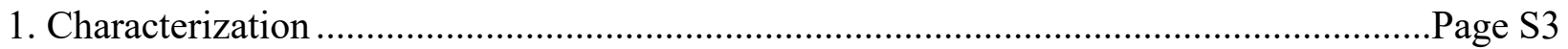

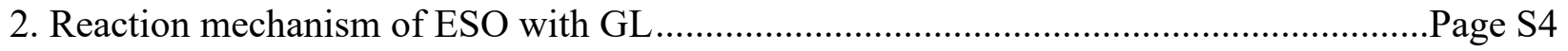

3. ${ }^{1} \mathrm{H}$ NMR spectrum of epoxidised soybean oil...................................................................... S4

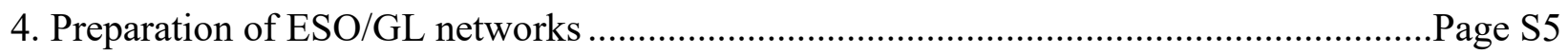

5. Curing reactivity study using a control system $\mathrm{ESO} / \mathrm{GA}$.................................................... S5

6. Thermal stability of TBD and ESO/GL/TBD mixture before the curing reactions..........Page S6

7. The possible transition structure of TBD with carboxyl groups of GL ................................. S7

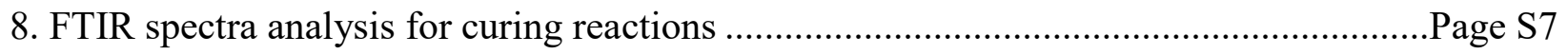

9. Chemical structure of carbenoxolone (CBX) and photo of cured ESO/CBX material ....Page S8

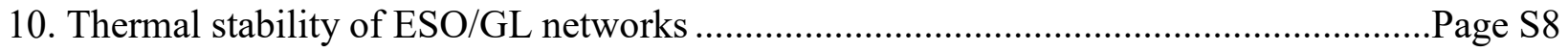

11. Topology freezing transition temperature of ESO/GL networks.......................................... S9

12. Thermodilatometry testing of ESO/GL networks............................................................ S10

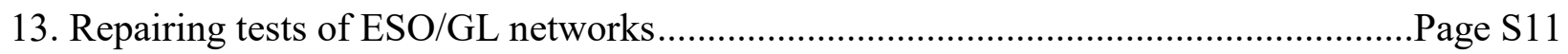

14. Apparent temperature shape memory of ESO/GL .......................................................... S12

15. Tensile tests for original and recycled samples ............................................................... S12

16. Photos of samples after lap-shear tests and the comparison between this work and other adhesives Page S13 


\section{Characterization}

Thermal stability test: Thermal stability was measured using a thermogravimetric analyzer (TGA, TA-Q50). Samples ( 5 mg) were loaded into alumina crucibles and scanned from room temperature to $700^{\circ} \mathrm{C}$ at a heating rate of $10^{\circ} \mathrm{C} /$ min under nitrogen atmosphere.

Differential scanning calorimeter (DSC) test: Differential scanning calorimeter (DSC, TAQ20) was used to investigate the curing behavior and determine the $T_{g}$ of vitrimers. The samples $(\sim 5 \mathrm{mg})$ were sealed in aluminum crucibles, and scanned at a heating rate of $5^{\circ} \mathrm{C} / \mathrm{min}$ for curing samples and raw materials, while at a heating rate of $20^{\circ} \mathrm{C} / \mathrm{min}$ for cured vitrimers to determine their $T_{g}$.

Fourier transform infrared spectroscopy (FTIR): Fourier transform infrared spectroscopy (FTIR) spectra were recorded on a spectrophotometer (Nicolet iS5). The sample was grinded with potassium bromide $(\mathrm{KBr}, 100 \mathrm{mg})$ in a mortar, and the mixture was compressed into a disk using a mould. All samples were scanned from 4000 to $400 \mathrm{~cm}^{-1}$.

Cell viability test: The samples with $15 \mathrm{mg}$ each piece were used for cell viability study. Before use, the samples were sterilized by immersion in sterile PBS for 30 min, followed by UV irradiation for 30 min. Fibroblasts NIH-3T3 were grown in Dulbecco's Modified EaGle's Medium (DMEM) supplemented with 10\% fetal bovine serum (FBS) in an atmosphere of $5 \% \mathrm{CO}_{2}$ at $37^{\circ} \mathrm{C}$. The cells were seeded in 48 -well culture plate with a density of $2 \times 10^{4}$ cells per well. After overnight incubation, the medium was replaced by fresh DMEM containing 10\% FBS and the sterile samples. After co-culturing for $24 \mathrm{~h}$ at $37^{\circ} \mathrm{C}, 10 \%$ of CellTiter-Blue reagent was added to each well and incubation continued for a further $3 \mathrm{~h}$ to perform the cell viability assay. The fluorescence intensity was measured at 560/590 nm $\left(E_{x} / E_{m}\right)$ by using a BioTek Synergy H1 microplate reader. 
Reaction mechanism of ESO with GL

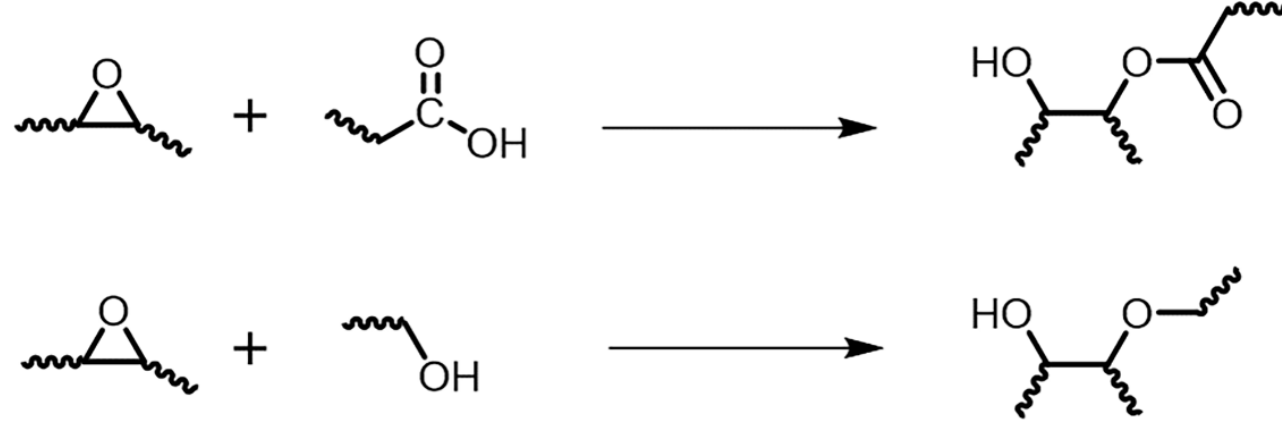

Scheme S1. Reaction mechanism of ESO with GL

${ }^{1}$ H NMR spectrum of epoxidised soybean oil

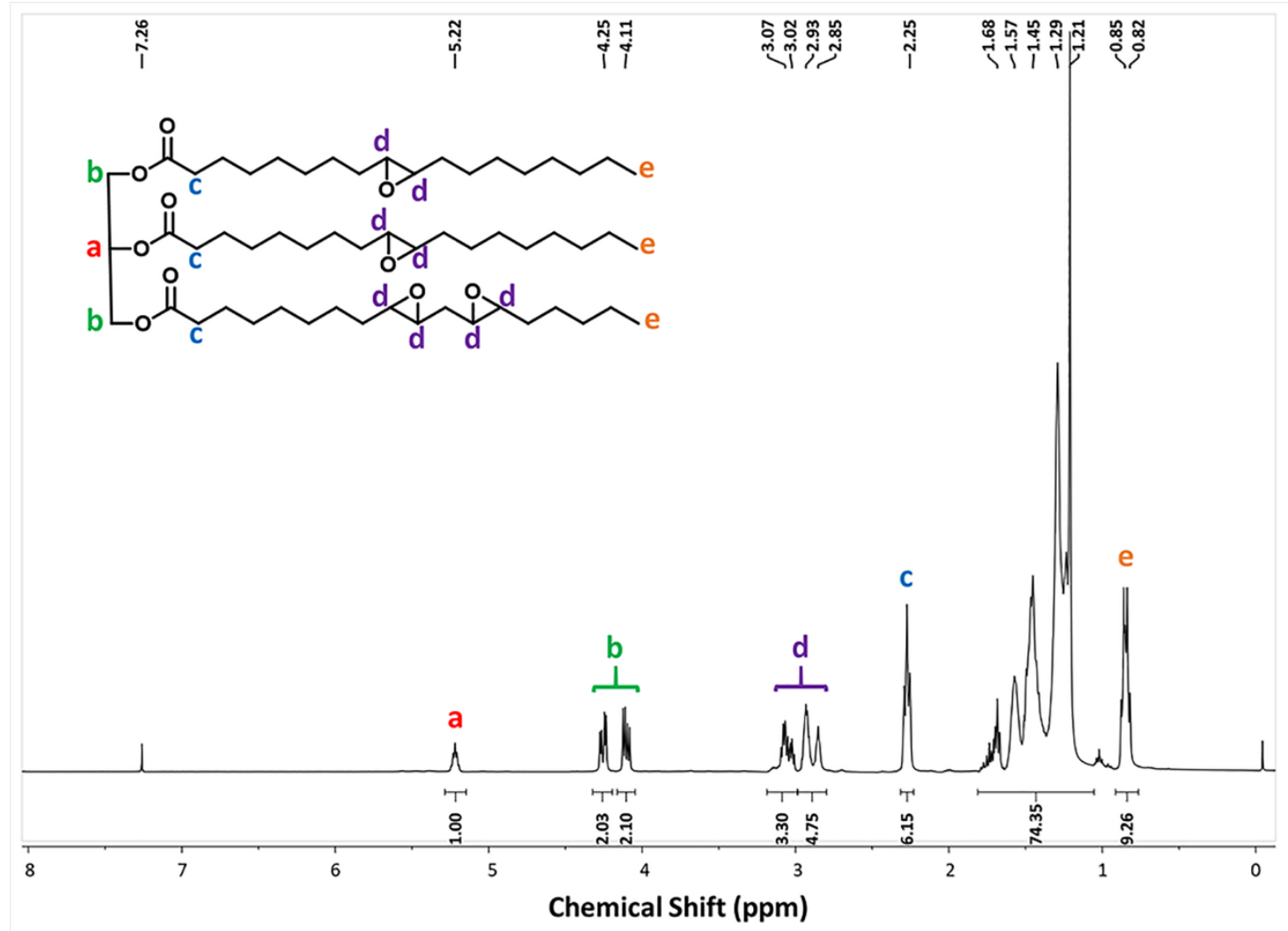

Figure S1. ${ }^{1} \mathrm{H}$ NMR spectrum of epoxidised soybean oil. 
Preparation of ESO/GL networks

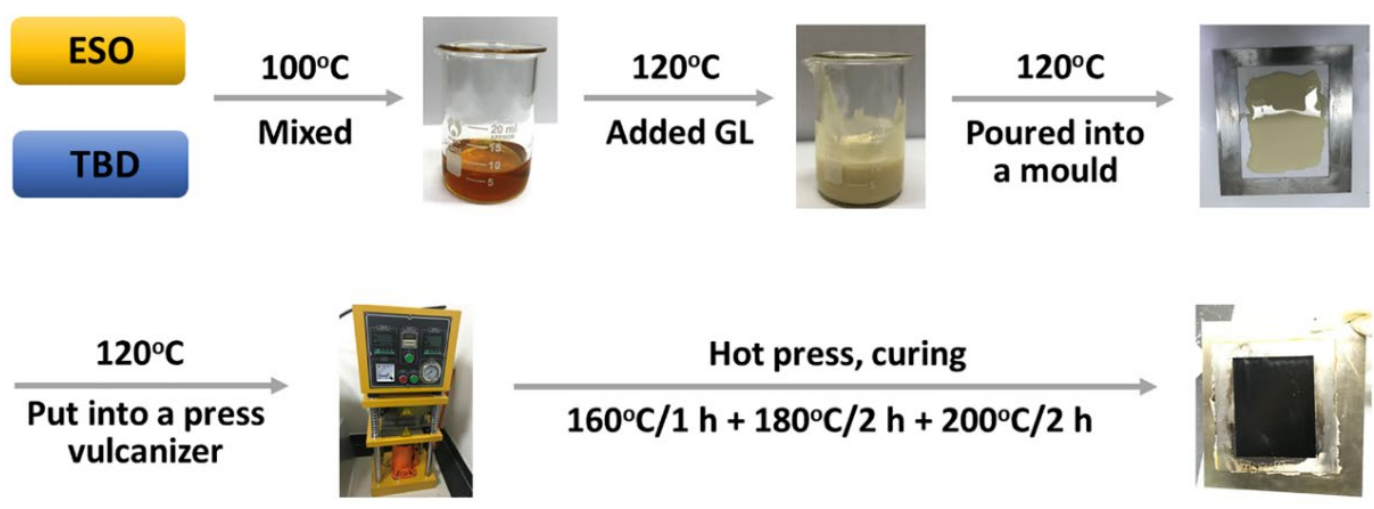

Figure S2. Photos of ESO/GL networks preparation.

Curing reactivity study using a control system ESO/GA.
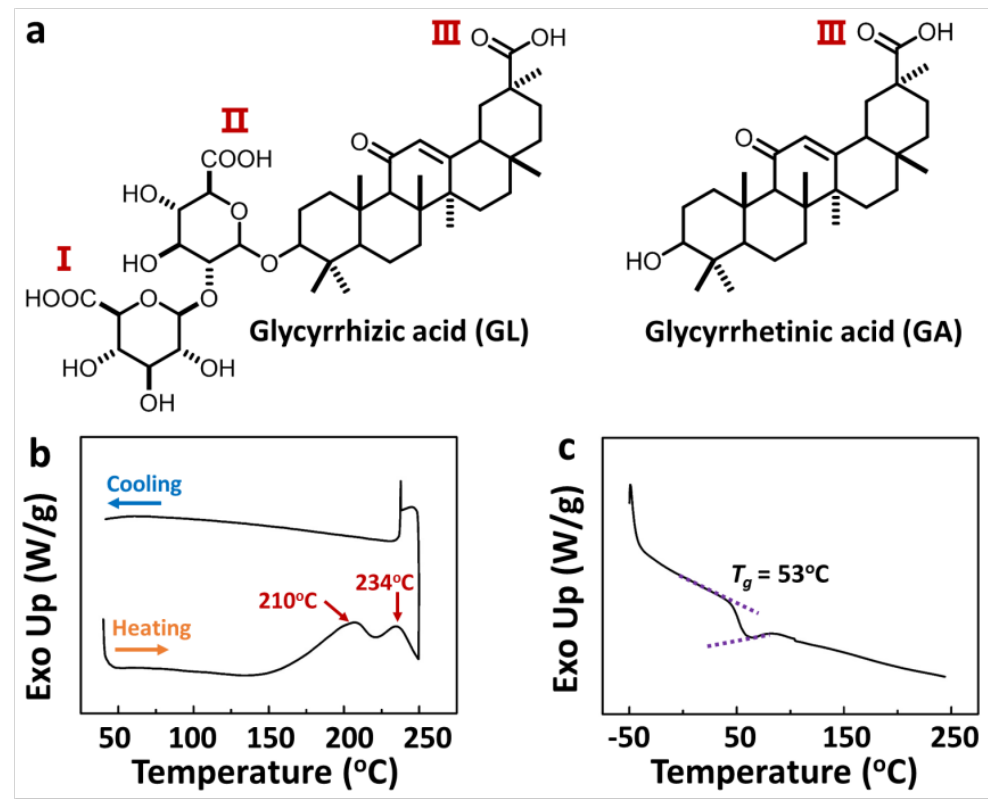

Figure S3. (a) Chemical structures of glycyrrhizic acid (GL) and glycyrrhetinic acid (GA). (b) DSC curve of the mixture of ESO/GA (carboxylic acid/epoxy $=0.5$, TBD $5 \mathrm{~mol} \%$ ) before curing at a heating and cooling rate $5^{\circ} \mathrm{C} / \mathrm{min}$. (c) DSC curve of $\mathrm{ESO} / \mathrm{GA}$ (carboxylic acid/epoxy $=0.5$, TBD $5 \mathrm{~mol} \%$ ) material after curing at a heating rate $20^{\circ} \mathrm{C} / \mathrm{min}$. 
Thermal stability of TBD and ESO/GL/TBD mixture before curing reactions
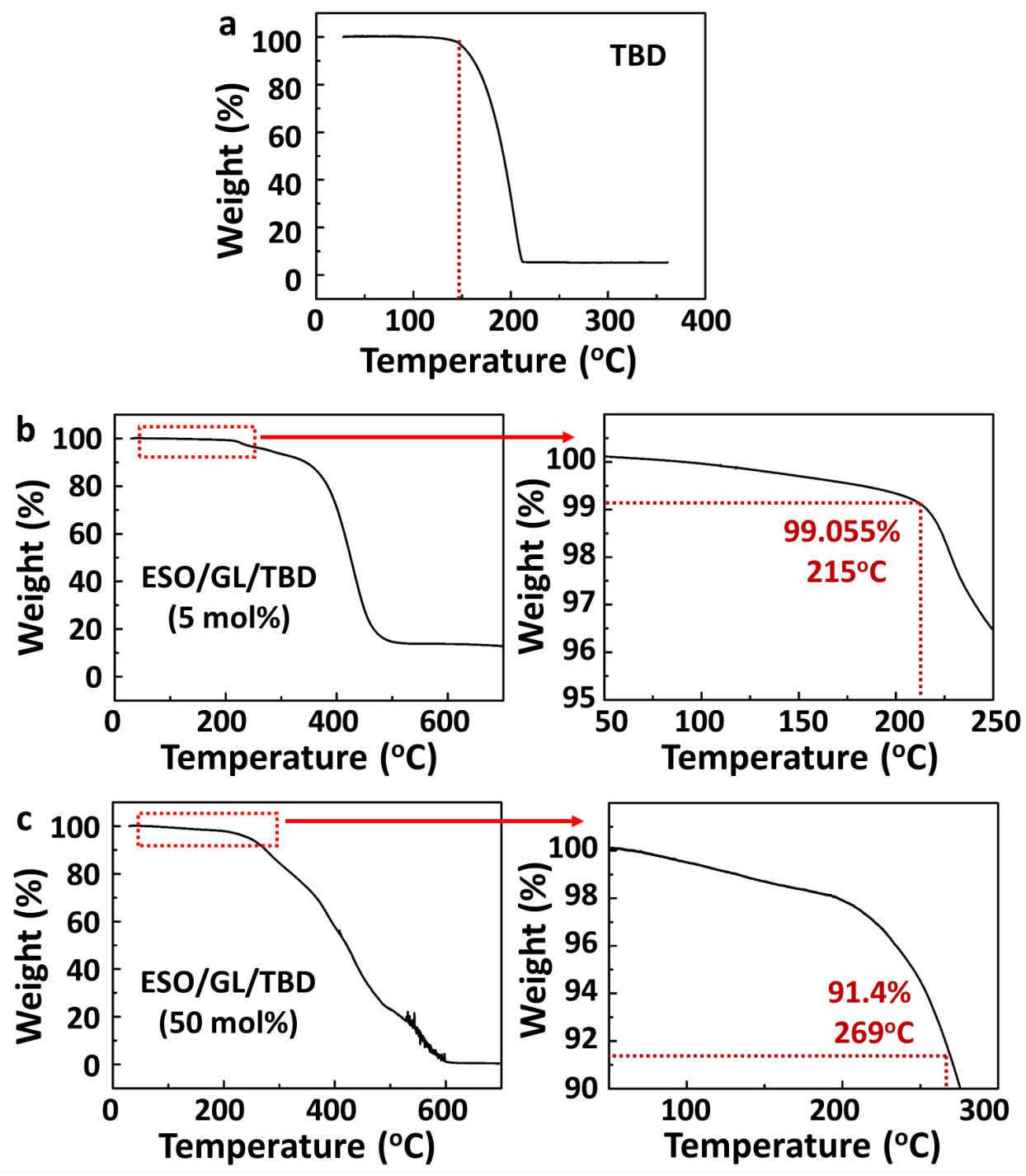

Figure S4. Thermogravimetic analysis of (a) pure TBD, (b) the mixture of ESO/GL/TBD (TBD content: $5 \mathrm{~mol} \%, 0.945 \mathrm{wt} \%$ ), and (c) the mixture of ESO/GL/TBD (TBD content: $50 \mathrm{~mol} \%, 8.6$ wt $\%$ ) before curing with $\mathrm{N}_{2}$ atmosphere at a heating rate of $10^{\circ} \mathrm{C} / \mathrm{min}$. 
The possible transition structure of TBD with carboxyl groups of GL
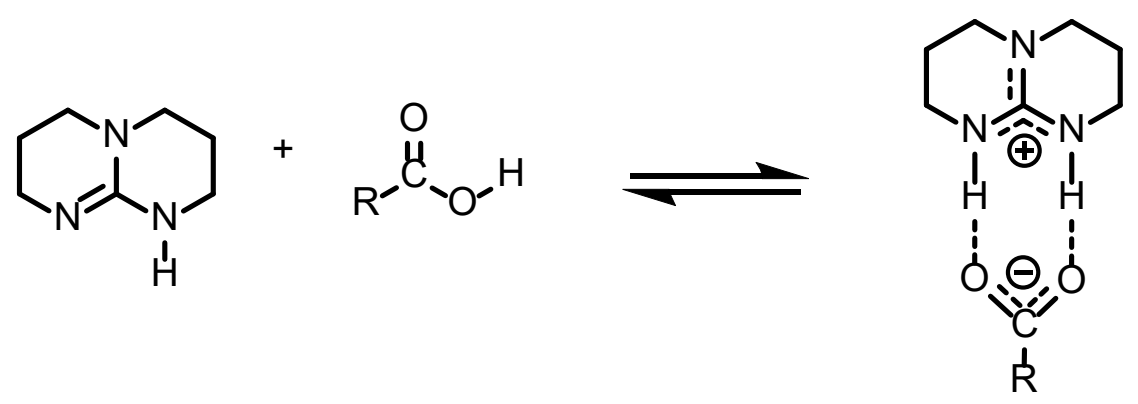

Scheme S2. The possible transition structure of TBD with carboxyl groups of GL.

FTIR spectra analysis for curing reactions

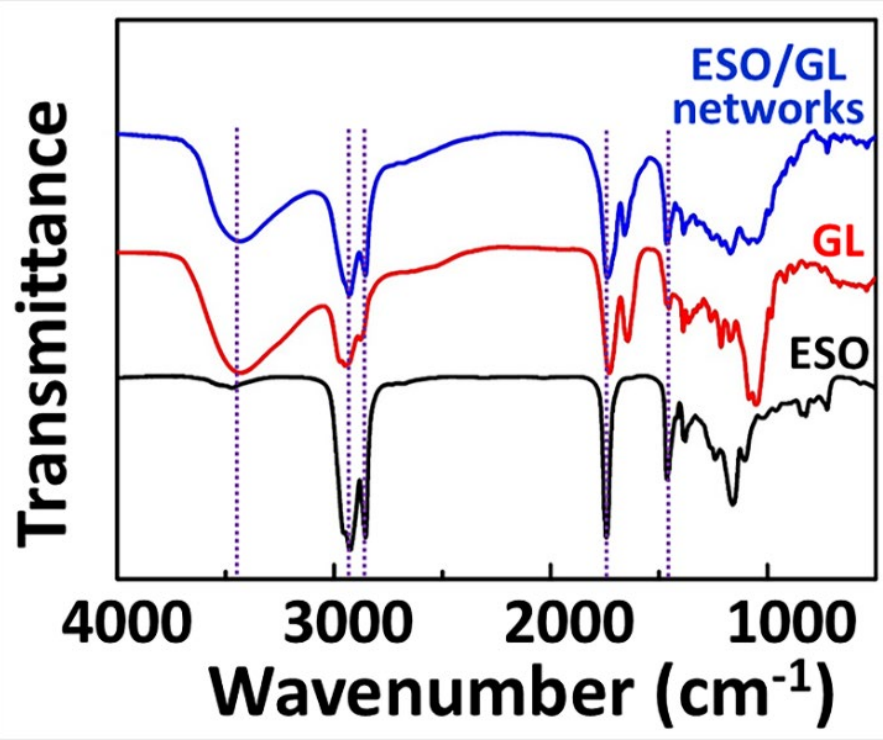

Figure S5. FTIR spectra of ESO, GL and ESO/GL networks (R = 0.5, TBD $5 \mathrm{~mol} \%$ ) ranging from 500 to $4000 \mathrm{~cm}^{-1}$. The signals at $3430,2925,1740,1730$, and $1655 \mathrm{~cm}^{-1}$ were assigned to hydroxyl, methylene, ester, carboxyl and ketone groups from backbones of ESO and GL. 
Chemical structure of carbenoxolone (CBX) and photo of cured ESO/CBX material

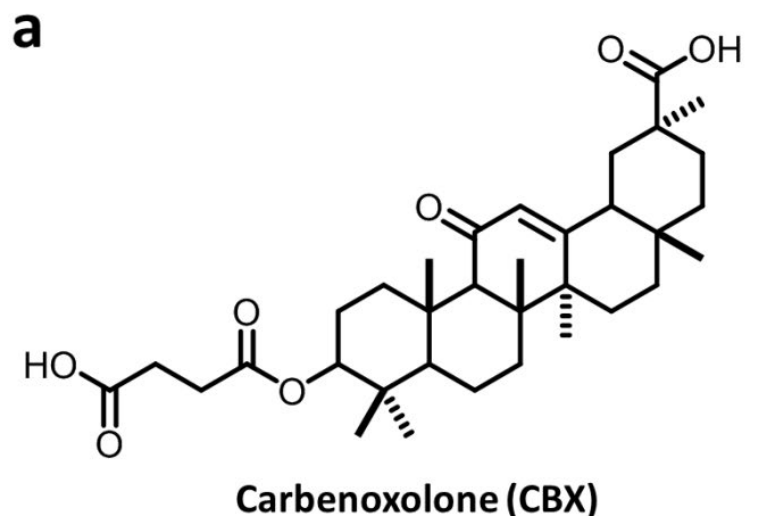

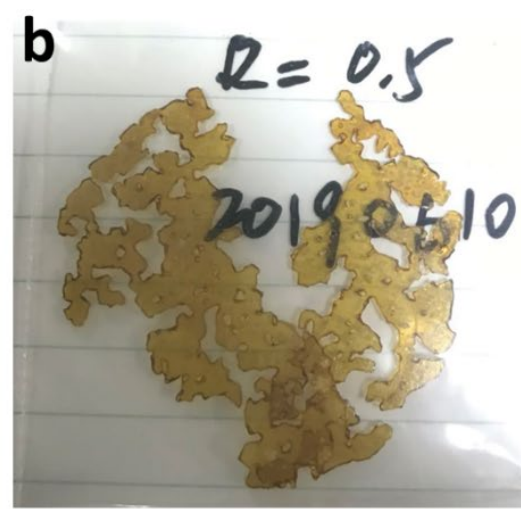

Figure S6. (a) Chemical structure of carbenoxolone (CBX), and (b) digital photo of cured $\mathrm{ESO} / \mathrm{CBX}$ (carboxylic acid/epoxy $=0.5$, TBD $5 \mathrm{~mol} \%$ ) material with background " $\mathrm{R}=0.5$ and 20190610”.

Thermal stability of ESO/GL networks

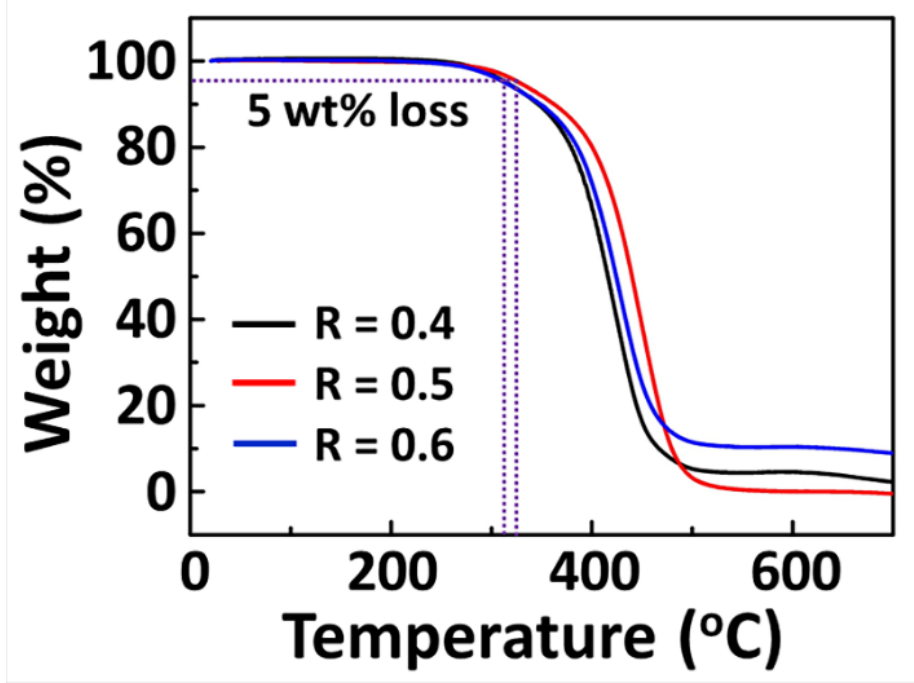

Figure S7. TGA curves of ESO/GL networks $(\mathrm{R}=0.4,0.5,0.6$; TBD $5 \mathrm{~mol} \%)$. 


\section{Topology freezing transition temperature of ESO/GL networks}

Equation S1 was obtained from Arrhenius law:

$$
y=13.4312 x-22.4288(\mathrm{r}=0.9947)
$$

The Maxwell relation (equation S2) below is used to calculate $\mathrm{T}_{v}$ which is defined as the point at the viscosity $\eta=10^{12} \mathrm{~Pa} \mathrm{~S}^{-1}$. The shear modulus $G$ was estimated from tensile modulus $\left(E^{\prime}\right)$ as measured by DMA with the relation. $E^{\prime}$ of the sample was calculated as the average modulus at temperature ranging from 140 to $200^{\circ} \mathrm{C}$ from the modulus-temperature curves (Figure $2 \mathrm{~d}$ ). The average plateau modulus of the sample is $0.16 \mathrm{MPa}$. The Poisson's ratio $v$ is chosen as the value 0.5 , which is usually used for rubbers.

$$
\begin{gathered}
\eta=G \tau^{*} \\
G=\frac{E^{\prime}}{2(1+v)}
\end{gathered}
$$

Consequently, $G=0.16 /(2 \times 1.5)=5.33 \times 10^{4} \mathrm{~Pa}$, $\tau^{*}=\eta / G=10^{12} /\left(5.33 \times 10^{4}\right)=1.88 \times 10^{7} \mathrm{~s}$, $\ln \tau^{*}=\ln \left(1.88 \times 10^{7}\right)=16.75$.

Using equation $\mathrm{S} 1,16.75=13.4312 x-22.4288, x=2.92$

Thereby, $1000 / T_{v}=2.92, T_{v}=342.47 \mathrm{~K}=69^{\circ} \mathrm{C}$. 


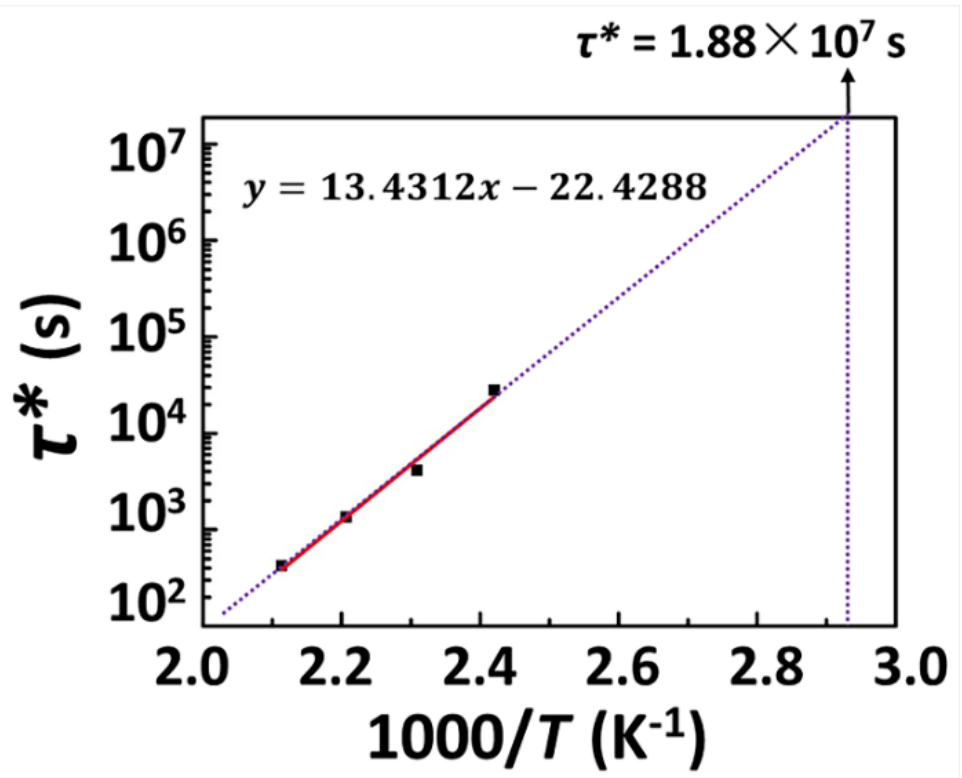

Figure S8. Topology freezing transition temperature calculated using equation S1.

\section{Thermodilatometry testing of ESO/GL networks}

The malleability temperature $T_{\text {mall }}$ for ESO/GL networks $(\mathrm{R}=0.5$, TBD $5 \mathrm{~mol} \%)$ using DMA controlled force model. A notable increase in the expansion coefficient at $138^{\circ} \mathrm{C}$ was defined as $T_{\text {mall }}$.

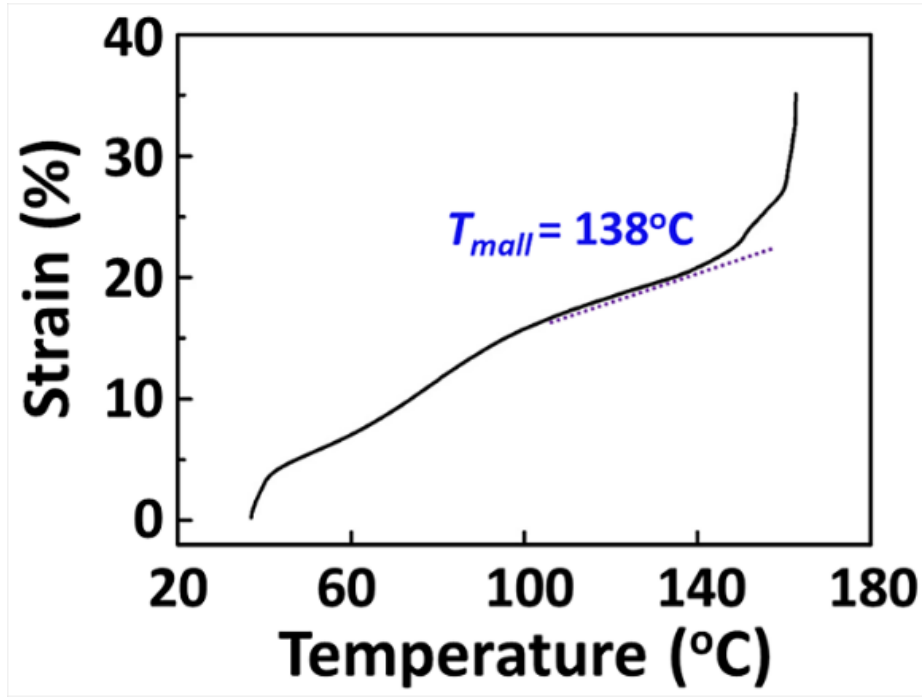

Figure S9. Curve for thermodilatometry of ESO/GL networks ( $\mathrm{R}=0.5$, TBD $5 \mathrm{~mol} \%)$. 


\section{Repairing tests of ESO/GL networks}

For $\mathrm{R}=0.4$, the width of the crack decreased from 77 to $17 \mu \mathrm{m}$ within $5 \mathrm{~min}$, and for $\mathrm{R}=0.6$ the width nearly disappeared after $5 \mathrm{~min}$, exhibiting the great repairing ability.

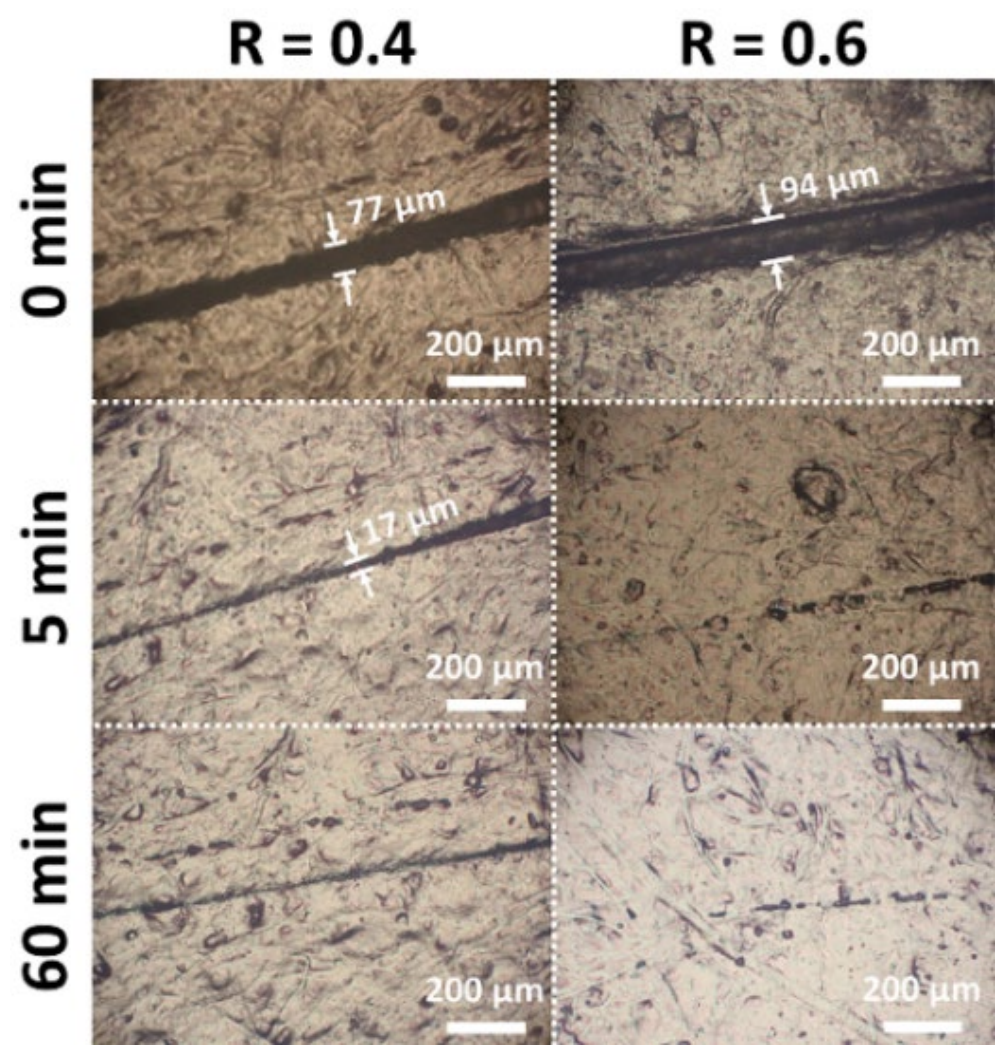

Figure S10. Optical microscope images of ESO/GL networks $(\mathrm{R}=0.4,0.6$; TBD $5 \mathrm{~mol} \%)$ during the repairing process $(0 \mathrm{~min}, 5 \mathrm{~min}$ and $60 \mathrm{~min})$. 


\section{Apparent temperature shape memory of ESO/GL}

Apparent temperature shape memory of ESO/GL networks $(\mathrm{R}=0.5$, TBD $5 \mathrm{~mol} \%)$ was shown in Movie S2 and Movie S3. In Movie S2, a flat sample was heated using hands and fixed to an "S" and a "chair", respectively. Finally, it was recovered to the original shape. In Movie S3, a bent "chair" was set on the hands, and gradually became to a flat sample with an angle approach $180^{\circ}$ within $100 \mathrm{~s}$ upon heating by hands.

\section{Tensile tests for original and recycled samples}

Samples after tensile tests were shown in Figure S6. It can be observed clearly that ESO/GL networks was broken neatly, while for recycled sample it was broken like zigzag. It was assumed that due to the incompleted TERs at interfaces between joined pieces, the cracks would develop along the weak interfacs, thus resulting in the decrease in tensile strength of recycled samples.
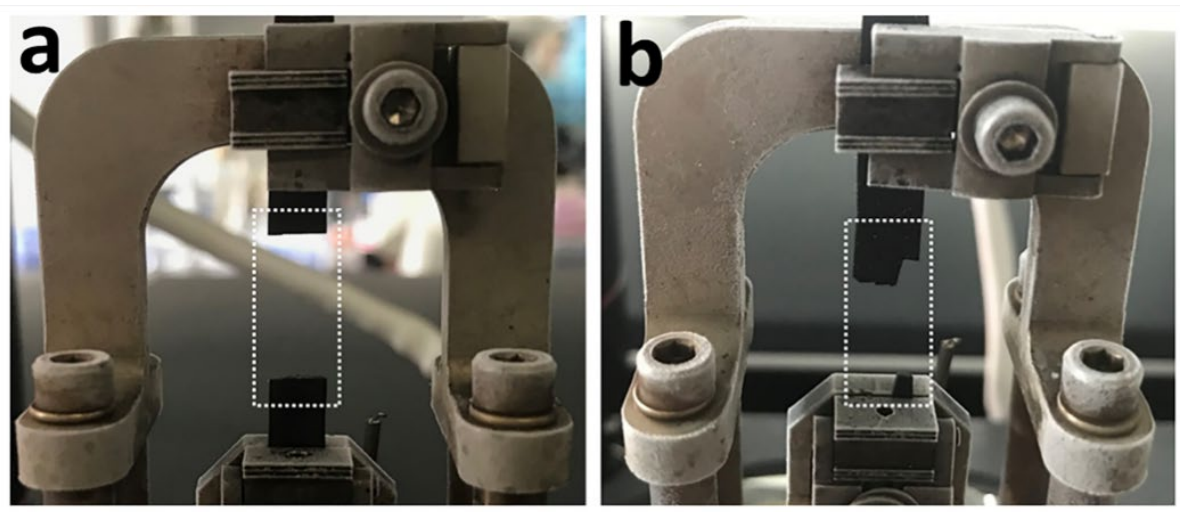

Figure S11. Photos of tensile tests for original (a) and recycled (b) samples. 

adhesives

Original

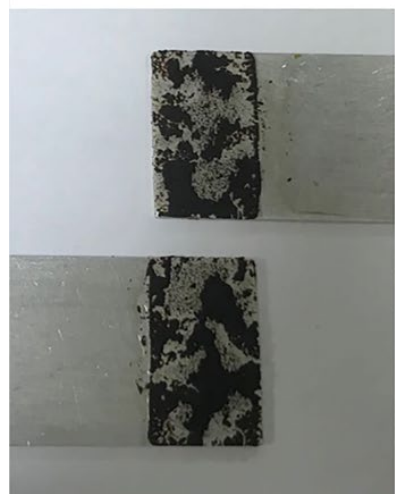

Repaired

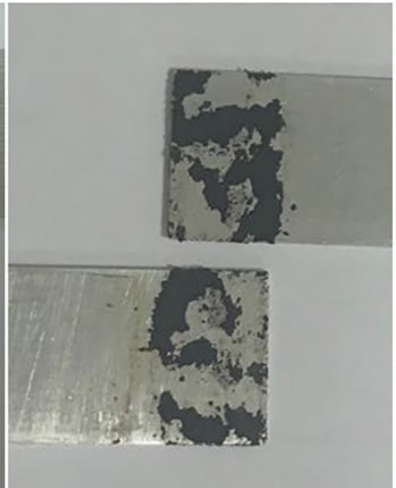

Recycled

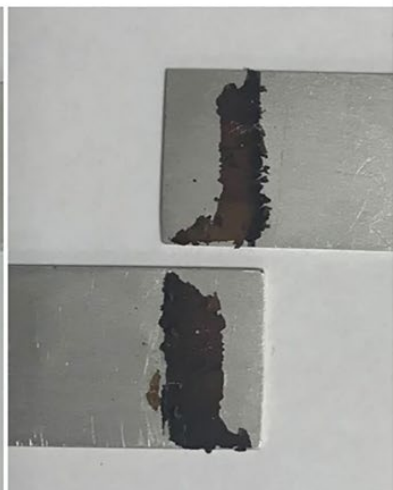

Figure S12. Photos of original, repaired and recycled samples after lap-shear tests.

Table S1. Lap-shear properties of this work and other reports.

\begin{tabular}{ccccc}
\hline $\begin{array}{c}\text { Lap-shear } \\
\text { strength } \\
\text { (aluminum) }\end{array}$ & Biobased & $\begin{array}{c}\text { Can be } \\
\text { repaired }\end{array}$ & $\begin{array}{c}\text { Can be } \\
\text { recycled }\end{array}$ & Reference \\
\hline $0.6 \mathrm{MPa}$ & $\sqrt{ }$ & $\times$ & $\times$ & Green Chem., 2013, 15, 3360 \\
$6.5 \mathrm{MPa}$ & $\sqrt{ }$ & $\sqrt{ }$ & $\times$ & Green Chem., 2018, 20, 2995 \\
$24 \mathrm{MPa}$ & $\times$ & $\sqrt{ }$ & $\times$ & J. Mater. Chem. A, 2017, 5, 21169 \\
$4-6 \mathrm{MPa}$ & $\times$ & $\times$ & $\times$ & Int. J. Adhes. Adhes., 2006, 29, 36 \\
$13-19 \mathrm{MPa}$ & $\sqrt{ }$ & $\times$ & $\times$ & RSC Adv., 2018, 8, 26948 \\
$0.2-1.6 \mathrm{MPa}$ & $\sqrt{ }$ & $\sqrt{ }$ & $\times$ & Macromolecules, 2019, 52, 3646 \\
$\mathbf{3 . 4 2} \mathrm{MPa}$ & $\sqrt{ }$ & $\sqrt{ }$ & $\sqrt{ }$ & This work \\
\hline
\end{tabular}

